\title{
Target categorization of aerosol and clouds by continuous multiwavelength-polarization lidar measurements
}

\author{
Holger Baars, Patric Seifert, Ronny Engelmann, and Ulla Wandinger \\ Leibniz Institute for Tropospheric Research (TROPOS), Permoser Str. 15, 04318 Leipzig, Germany \\ Correspondence to: Holger Baars (baars@tropos.de)
}

Received: 20 December 2016 - Discussion started: 10 February 2017

Revised: 29 May 2017 - Accepted: 8 June 2017 - Published: 1 September 2017

\begin{abstract}
Absolute calibrated signals at 532 and $1064 \mathrm{~nm}$ and the depolarization ratio from a multiwavelength lidar are used to categorize primary aerosol but also clouds in high temporal and spatial resolution. Automatically derived particle backscatter coefficient profiles in low temporal resolution $(30 \mathrm{~min})$ are applied to calibrate the lidar signals. From these calibrated lidar signals, new atmospheric parameters in temporally high resolution (quasi-particle-backscatter coefficients) are derived. By using thresholds obtained from multiyear, multisite EARLINET (European Aerosol Research Lidar Network) measurements, four aerosol classes (small; large, spherical; large, non-spherical; mixed, partly nonspherical) and several cloud classes (liquid, ice) are defined. Thus, particles are classified by their physical features (shape and size) instead of by source.

The methodology is applied to 2 months of continuous observations ( $24 \mathrm{~h}$ a day, 7 days a week) with the multiwavelength-Raman-polarization lidar Polly ${ }^{X T}$ during the High-Definition Clouds and Precipitation for advancing Climate Prediction $\left(\mathrm{HD}(\mathrm{CP})^{2}\right)$ Observational Prototype Experiment (HOPE) in spring 2013. Cloudnet equipment was operated continuously directly next to the lidar and is used for comparison. By discussing three $24 \mathrm{~h}$ case studies, it is shown that the aerosol discrimination is very feasible and informative and gives a good complement to the Cloudnet target categorization. Performing the categorization for the 2-month data set of the entire HOPE campaign, almost 1 million pixel $(5 \mathrm{~min} \times 30 \mathrm{~m})$ could be analysed with the newly developed tool. We find that the majority of the aerosol trapped in the planetary boundary layer (PBL) was composed of small particles as expected for a heavily populated and industrialized area. Large, spherical aerosol was observed mostly at the top of the PBL and close to the identi-
\end{abstract}

fied cloud bases, indicating the importance of hygroscopic growth of the particles at high relative humidity. Interestingly, it is found that on several days non-spherical particles were dispersed from the ground into the atmosphere.

\section{Introduction}

Aerosol and clouds are important atmospheric players influencing weather and climate. In contrast to long-lived gaseous components in the atmosphere, these components are short lived and feature a strong spatiotemporal variability. Aerosols act as cloud condensation nuclei and ice nucleating particles and are thus one major driver for cloud optical and microphysical properties and precipitation initiation. Because aerosol is emitted from various sources and is short-living, several aerosol types with different optical and microphysical properties exist in different heights of the atmosphere, influencing solar radiation and clouds in different ways. Therefore, the climate effects of aerosol directly and of aerosols on clouds (indirectly) are still very uncertain (IPCC, 2013).

In order to better quantify the spatiotemporal distribution of aerosol and clouds as well as to improve the determination of their interaction, it is essential to observe aerosol and clouds, preferably in 4-D, but realistically round the clock and vertically resolved. Active satellite-based sensors such as CALIPSO (Cloud-Aerosol Lidar and Infrared Pathfinder Satellite Observation; Winker et al., 2009), CloudSat (Stephens et al., 2002), CATS (Cloud-Aerosol Transport System; Yorks et al., 2016), and, planned for future space missions, Atmospheric Dynamics Mission Aeolus (Stoffelen et al., 2005) and EarthCARE (Earth Clouds, 
Aerosols and Radiation Explorer; Illingworth et al., 2015) cover the globe but with low temporal and spatial resolution. Thus, high-performance ground-based observations are also needed. Scientific networks such as Cloudnet (Illingworth et al., 2007) or the ARM (Atmospheric Radiation Measurement) Climate Research Facilities (Mather and Voyles, 2013) use different ground-based instruments at the same location (supersite) to gather as much information as possible in high temporal and spatial (i.e. vertical) resolution but at specific locations only. Cloudnet, for example, uses as minimum instrumentation a cloud radar, a ceilometer (a simple backscatter lidar), and a microwave radiometer (MWR) to characterize the atmosphere above the supersite. Cloudnet delivers several products, ranging from calibrated measurements to microphysical cloud properties. Very well known and widely used is the Cloudnet target categorization (Hogan and O'Connor, 2004), which classifies a series of different particle types in the observed atmospheric column (e.g. liquid droplets, ice crystals, aerosols). However, Cloudnet is not able to distinguish different aerosol types in its current state, which is a prerequisite to constrain aerosol-cloud-interaction studies and to improve the estimation of the radiative properties of aerosol.

Active remote sensing with lidar is a key technique for characterizing aerosol and allows capturing the atmospheric state on a vertically resolved basis usually covering the whole troposphere. For an intense characterization of aerosol type and properties, so-called multiwavelength lidars (MWLs) are applied using the synergistic information from different wavelengths, scattering mechanisms, and polarization states of the received light (e.g. Müller et al., 2007).

Optical aerosol properties have been widely investigated by using lidar profiles in low temporal resolution, applying the traditional Raman method (Ansmann et al., 1992b), the Klett-Fernald method (Klett, 1981; Fernald, 1984), and the depolarization method (e.g. Cairo et al., 1999) to determine the intensive properties (Ångström exponent, extinction-tobackscatter (lidar) ratio, particle depolarization ratio) of different aerosol types and their mixtures (Müller et al., 2007; Tesche et al., 2011; Ansmann et al., 2011; Burton et al., 2012; Pappalardo et al., 2013; Groß et al., 2013; Giannakaki et al., 2015; Amiridis et al., 2015; Sugimoto et al., 2014; Illingworth et al., 2015; Baars et al., 2016).

Based on such measurements, classification schemes for aerosol from high-resolution lidar measurements have been developed for space-borne lidars (CALIPSO, Omar et al., 2009; EarthCARE, Illingworth et al., 2015; Groß et al., 2015), airborne High Spectral Resolution Lidar (HSRL) measurements (Burton et al., 2012; Groß et al., 2013), some specific ground-based instruments (ARM, Darwin, Australia, Thorsen et al., 2015), and lidar networks focusing on the determination of mineral dust concentration in Asia (Asian Dust Network, AD-NET; Shimizu et al., 2010; Sugimoto et al., 2014).
Due to recent advances in hardware, small sophisticated ground-based MWLs (e.g. Polly ${ }^{X T}$ lidar systems, Engelmann et al., 2016), which can run unattended and autonomously $24 \mathrm{~h}$ a day, 7 days a week (24/7), have been developed and are deployed globally. Motivated by this technical progress, we aimed at developing a stand-alone tool for continuously running multiwavelength-polarization lidars for a basic categorization of the observed particles (targets) in analogy to the Cloudnet target categorization. With this tool, we want to obtain an estimate of the dominant type of backscatterer (molecules, aerosol types, clouds) which then can be used for further intensive studies and to complement the Cloudnet target categorization. For this approach we focus on the derivation of certain key parameters, which are not needed with high accuracy but are sufficient to perform a first estimate of certain particle types in the atmosphere. The basic lidar quantities used are the attenuated backscatter coefficients at 532 and $1064 \mathrm{~nm}$ (calibrated range-corrected lidar signal) and the calibrated volume linear depolarization ratio at $532 \mathrm{~nm}$. These key parameters are highly useful as they are available for many continuously measuring lidar systems worldwide, e.g. the lidars within PollyNET (Baars et al., 2016), AD-NET, and the space-borne lidar CALIPSO. From these lidar parameters, further products have been developed to allow a first-guess particle typing.

To develop this tool and demonstrate the feasibility, potential, and limitations of this approach, we have used the unique data set obtained during the High-Definition Clouds and Precipitation for advancing Climate Prediction $\left(\mathrm{HD}(\mathrm{CP})^{2}\right)$ Observational Prototype Experiment (HOPE; Macke et al., 2016) in western Germany. The MWL Polly XT (Engelmann et al., 2016) and the Cloudnet instruments (cloud radar, ceilometer, MWR) were deployed in the frame of the Leipzig Aerosol and Cloud Remote Observations System (LACROS, Bühl et al., 2013) next to each other at Krauthausen, Germany, continuously for 2 months in Spring 2013. Polly ${ }^{X T}$ is a sophisticated, compact, scientific multiwavelength lidar to which the quality-assurance procedures proposed by EARLINET (European Aerosol Research Lidar Network; Pappalardo et al., 2013) are applied. Without such high-quality measurements, a proper aerosol characterization as described in the following is not possible. The collocation of the instruments makes the derived data set a perfect environment for developing an aerosol classification from MWL while the Cloudnet categorization can be performed in parallel.

For the HOPE data set, we perform a so-called absolute calibration on the lidar observations from automatically derived particle backscatter coefficient profiles (Baars et al., 2016) and derive atmospheric parameters in high temporal resolution, which allow us to estimate size and shape and finally type of the particles in the atmosphere. This basic typing can then be used for detecting different aerosol layers, for further research like on aerosol-cloud-interaction processes, as input for calibration procedures to automati- 
cally retrieve optical properties of the observed particles (e.g. D'Amico et al., 2015), and finally even for retrieving microphysical properties (Müller et al., 2016; Veselovskii et al., 2015) which then may lead to an advanced particle categorization (e.g. HETEAC, hybrid end-to-end aerosol classification model; Wandinger et al., 2016).

The paper is structured as follows: first, the HOPE campaign, i.e. location and instrumentation, is briefly introduced in Sect. 2. The methodology to derive quantitative lidar parameters with temporal high resolution is explained in Sect. 3. Next, the new target categorization is introduced and intensively discussed by means of three case study days during HOPE in Sect. 4. The new methodology was applied on the complete HOPE data set and analysed in Sect. 5. Finally, conclusions are drawn in Sect. 6.

\section{HOPE}

During the $\mathrm{HD}(\mathrm{CP})^{2}$ Observational Prototype Experiment (HOPE; Macke et al., 2016), the multiwavelength-Raman lidar Polly IfT $_{\text {XT }}^{\text {XT }}$ (Althausen et al., 2009; Engelmann et al., 2016) was deployed at Krauthausen $\left(50.879746^{\circ} \mathrm{N}, 6.414571^{\circ} \mathrm{E}\right.$, 110 ma.s.1.), near Jülich, western Germany, in April and May 2013 as part of the LACROS facility (Bühl et al., 2013). A detailed description of the campaign together with the prevailing meteorological conditions can be found in Macke et al. (2016).

Polly $\mathrm{XT}$ (system version labelled "IfT", compare Engelmann et al., 2016) is an automatic, portable multiwavelengthpolarization Raman lidar with automatic calibration procedures of the latest standards which was operated in 24/7 mode during HOPE. The lidar emits pulses of linearly polarized light at 355,532 , and $1064 \mathrm{~nm}$ at a repetition frequency of $20 \mathrm{~Hz}$. The receiver has seven channels detecting the elastically backscattered light at the three aforementioned wavelengths, the cross-polarized light at $532 \mathrm{~nm}$, and the vibrational Raman scattered light at 387, 407, and $607 \mathrm{~nm}$. With Polly IfT, aerosol profiles can be obtained with $30 \mathrm{~m}$ vertical and $30 \mathrm{~s}$ temporal resolution. The full overlap between the laser beam and the receiver field of view is about $1500 \mathrm{~m}$; thus, an overlap correction (Wandinger and Ansmann, 2002) is applied below this height. The lidar was operated in photon-counting mode. The system is pointed $5^{\circ}$ offzenith to prevent the detection of specular reflection by the planar planes of horizontally oriented ice crystals (Hu et al., 2009; Westbrook et al., 2009). A detailed description of the system including a quality assessment can be found in Engelmann et al. (2016).

Furthermore, a cloud radar, a Doppler wind lidar, a ceilometer, and an AERONET (Aerosol Robotic Network) sun photometer were deployed next to the lidar as part of the LACROS facility. From these instruments, Cloudnet products (Illingworth et al., 2007) and AERONET products (Holben et al., 2001) are available. Because of radar scanning ex- periments during HOPE in Jülich, Cloudnet products which require vertically pointing measurements are sporadically unavailable for this campaign.

\section{Methodology}

In modern multiwavelength lidars, a number of different receiving channels are installed to make use of as much information from the atmosphere as possible (elastic and Raman [inelastic] scattering, change in polarization state of emitted light due to scattering, etc.). In this way, high-quality aerosol products are obtained on a vertically resolved basis. However, because of the high background noise, Raman lidar observations during daytime are challenging. Therefore, for continuous (24/7) measurements, we concentrate on the use of channels for elastic backscattering, including depolarization. The key challenge to succeed with automated aerosol retrievals is the calibration of the lidar signals. There are two main tasks necessary before an automated aerosol target categorization can be performed: the calibration of the backscatter profiles and the calibration of the depolarization products.

\subsection{Calibration of backscatter}

The backscatter signal strength $P$ (number of counted photons per $30 \mathrm{~s}$ and $30 \mathrm{~m}$ in the case of the lidar system used here) for a certain range $R$ at the wavelength $\lambda$ can be described for each channel by

$$
\begin{aligned}
& P^{\lambda}(R)=C^{\lambda} \frac{O^{\lambda}(R)}{R^{2}}\left[\beta_{\mathrm{par}}^{\lambda}(R)+\beta_{\mathrm{mol}}^{\lambda}(R)\right] \\
& \times \exp \left\{-2 \int_{0}^{R}\left[\alpha_{\mathrm{par}}^{\lambda}(r)+\alpha_{\mathrm{mol}}^{\lambda}(r)\right] \mathrm{d} r\right\},
\end{aligned}
$$

with the wavelength-dependent lidar system parameter $C^{\lambda}$ containing all instrument-relevant quantities, the overlap function $O^{\lambda}(R)$, the molecular (subscript mol) and particle (subscript par) backscatter coefficient $\beta$, and the atmospheric transmissivity described by the molecular and particle extinction coefficient $\alpha$. The molecular backscatter and extinction coefficients can easily be calculated from pressure and temperature profiles obtained from radio soundings or model output with well-known scattering formulas (Bucholtz, 1995). For usual lidar applications, the particle backscatter coefficient is obtained by applying the Raman (Ansmann et al., 1992a) or Klett-Fernald method (Klett, 1981; Fernald, 1984) to the received signals. With these methods, the lidar signal is calibrated in a certain height range of the atmosphere for which only molecular scattering is assumed. However, these methods require appropriate weather conditions (e.g. no low-level clouds) and temporal averaging over typically at least $30 \mathrm{~min}$ to increase the signal-to-noise ratio (SNR) in the calibration height region. Thus, for temporally high-resolved 24/7 aerosol analysis, 
these methods are not applicable. Therefore, we perform an absolute lidar calibration by deriving the lidar system parameter $C^{\lambda}$ to obtain foremost the attenuated backscatter coefficient.

For the measurements performed during HOPE, $C^{\lambda}$ was derived from particle backscatter coefficient profiles, which were automatically computed with the Raman or KlettFernald methods at $30 \mathrm{~min}$ resolution as described in Baars et al. (2016). From these profiles, $C^{\lambda}(R)$ can be calculated by rearranging Eq. (1) to

$$
\begin{aligned}
& C^{\lambda}(R)=\frac{P^{\lambda}(R) R^{2}}{\left[\beta_{\mathrm{par}}^{\lambda}(R)+\beta_{\mathrm{mol}}^{\lambda}(R)\right] O^{\lambda}(R)} \\
& \times \exp \left\{2 \int_{0}^{R}\left[\alpha_{\mathrm{par}}^{\lambda}(r)+\alpha_{\mathrm{mol}}^{\lambda}(r)\right] \mathrm{d} r\right\} .
\end{aligned}
$$

The final $C^{\lambda}$ is computed as the mean value of a height window of $1000 \mathrm{~m}$ above the full overlap height (i.e. $1500 \mathrm{~m}$ in the case of Polly $\mathrm{XTT}_{\mathrm{IfT}}^{\mathrm{XT}}$ ) and is considered to be height independent. $C^{\lambda}$ is valid for the recorded raw resolution of $30 \mathrm{~m}, 30 \mathrm{~s}$, and repetition rate of $20 \mathrm{~Hz}$ of the lidar system used here. For the automatically retrieved particle backscatter profiles from the Polly systems, all known instrumental issues (e.g. background subtraction) which could cause heightdependent effects were corrected, except for the partial overlap in the lowermost part of the lidar profile described by $O^{\lambda}(R)$, which is a substantial feature of each lidar system. For that reason and because the particle extinction coefficient derived with the Raman method is only available during nighttime, we introduced a two-step approach to estimate the particulate transmission needed to solve Eq. (2). First, we calculate the particle extinction coefficient profile derived from the particle backscatter coefficient profile (Raman or Klett - depending on time of day) multiplied with a constant lidar ratio of $55 \mathrm{sr}$ as a good compromise of the lidar ratio values observed during HOPE and at other European continental sites (clean and polluted continental aerosol, desert dust, and smoke; Mattis et al., 2004; Müller et al., 2007; Groß et al., 2013; Schwarz, 2016; Baars et al., 2016). Second, we assume height-independent extinction below $500 \mathrm{~m}$ to account for both the incomplete overlap within the lidar profile and atmospheric variability in the lowermost troposphere. At $500 \mathrm{~m}$, already more than $80 \%$ of the overlap between the laser and the telescope field of view is reached and the applied overlap correction profile can correct the signal with high accuracy up to the full overlap height. Finally, an extinction profile from the surface up to the height of interest is available to calculate the particulate transmission in Eq. (2).

Figure 1 shows the daily mean lidar system parameters calculated as described above for the HOPE campaign. For some days, no calculation was possible due to unfavourable weather conditions and thus the unavailability of automatically retrieved backscatter coefficient profiles for calibration.
Vertical dashed lines indicate set-up changes in the lidar. Even though we tried to minimize set-up changes (neutraldensity filters, overlap adjustment, laser energy, emissionwindow cleaning), several changes were necessary but not always influencing the derived lidar system parameter.

One can see that the lidar system parameter is relatively stable and only some of the set-up changes have caused a significant change in $C^{\lambda}$. However, there are also periods were there was a significant change of $C^{\lambda}$ even without changes in the set-up, e.g. between 21 April 2013 and 1 May 2013. It was found that changes in the indoor temperature of the cabinet due to air conditioning malfunctioning had led to a change of the alignment (e.g. the overlap between the receiver field of view and the laser beam) and thus a change in $C^{\lambda}$ during this period. On 2 days (25 April and 10 May), the corresponding data were therefore partly not considered in the analysis. The daily mean lidar system parameter can finally be obtained with an SD (standard deviation) of less than $20 \%$. The relative change of the lidar system parameter is similar for all three wavelengths, even though it looks different in Fig. 1 due to the scaling applied. On 3 days (18, 25 April, and 10 May), for which multiple system set-up changes were performed, more than one lidar system parameter was used to account for these set-up changes. In all other cases, the daily mean system parameter was used when available, otherwise the closest lidar system parameter from the days before or after was applied, to calculate the calibrated attenuated backscatter coefficient derived by dividing the range-corrected signal with the lidar system parameter:

$$
\begin{aligned}
& \beta_{\mathrm{att}}^{\lambda}(R)=\frac{P^{\lambda}(R) R^{2}}{C^{\lambda}}=\left[\beta_{\mathrm{par}}^{\lambda}(R)+\beta_{\mathrm{mol}}^{\lambda}(R)\right] \\
& \times \exp \left\{-2 \int_{0}^{R}\left[\alpha_{\mathrm{par}}^{\lambda}(r)+\alpha_{\mathrm{mol}}^{\lambda}(r)\right] \mathrm{d} r\right\} .
\end{aligned}
$$

\subsection{Calibration of depolarization ratio}

The calibration of the depolarization measurements of Polly ${ }^{\mathrm{XT}}$ systems is done with the so-called $\Delta 90^{\circ}$ method (Freudenthaler, 2016) in agreement with EARLINET standards. For this purpose, a motorized filter wheel is implemented in the receiver unit of Polly ${ }^{\mathrm{XT}}$ to perform the $\Delta 90^{\circ}$ calibration automatically three times a day. The procedure delivers the calibration constant $V^{*}$, which was found to be very stable for HOPE as shown in Fig. 2. It relies on the ratio of two signals and thus is invariant against most changes in the lidar set-up (e.g. laser power, overlap). For days at which inappropriate weather conditions did not allow the determination of $V^{*}$, a standard value (mean of HOPE) is used. Only changes in the neutral-density filter set-up of the polarization channels will affect the depolarization calibration constant, which was not the case during HOPE. Thus, we consider the calibration as very accurate with an SD of less than $8 \%$ as seen in Fig. 2. By knowing the lidar-system- 


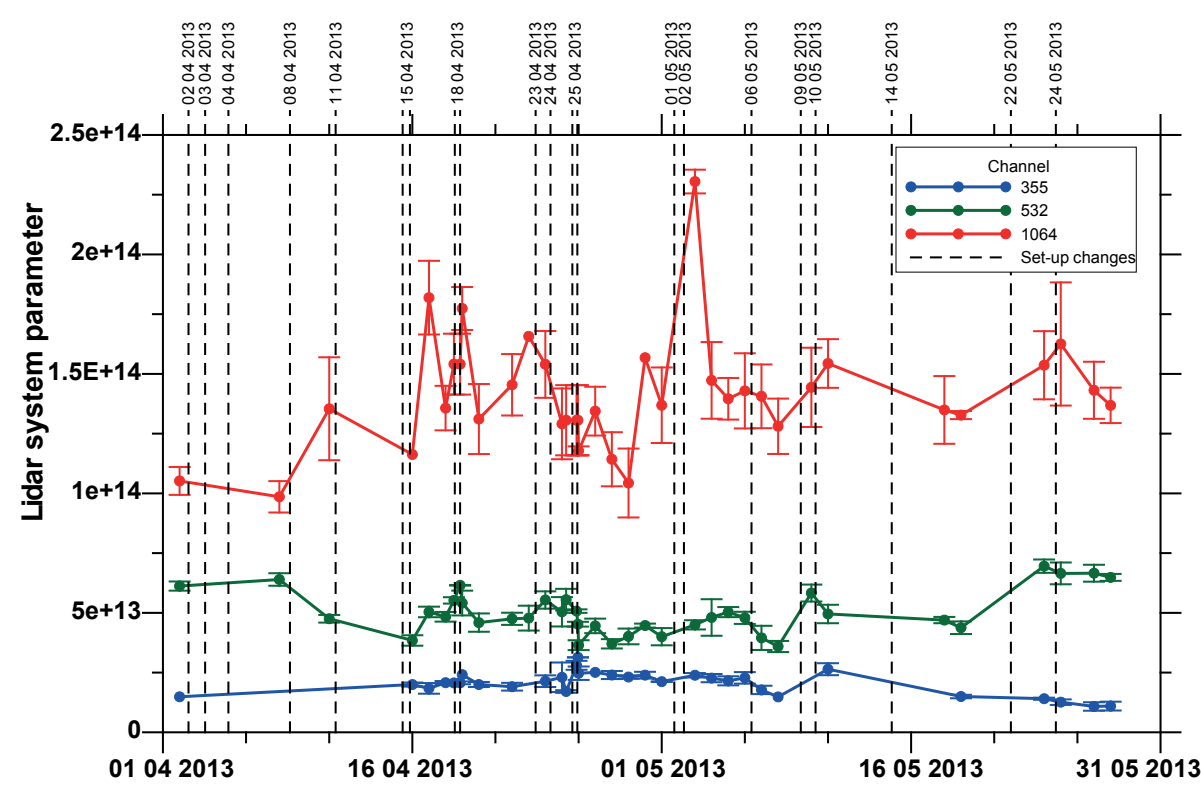

Figure 1. Lidar system parameter $C^{\lambda}$ for 355,532 , and $1064 \mathrm{~nm} . C^{\lambda}$ is given for the photon counts of the recorded raw resolution of $30 \mathrm{~m}$, $30 \mathrm{~s}$, and repetition rate of $20 \mathrm{~Hz}$ corrected for the range dependency $\left(R^{2}\right)$ in metres. Vertical lines indicate lidar set-up changes.

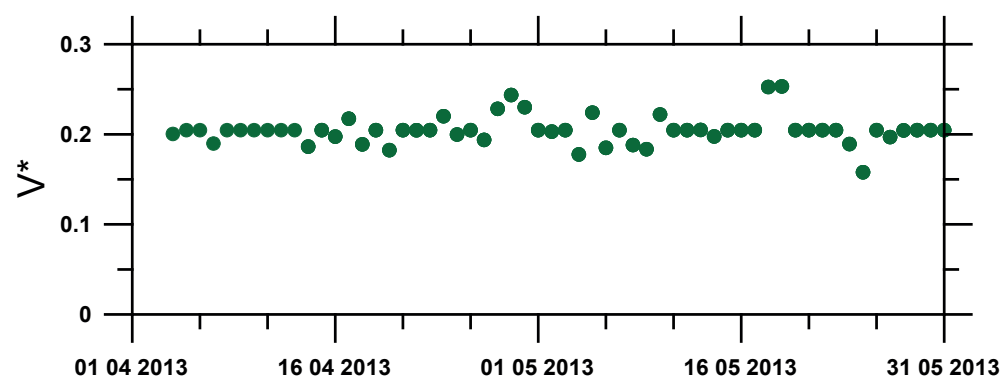

Figure 2. Daily depolarization calibration factor $V^{*}$ as derived during HOPE.

dependent transmission ratios $D_{\mathrm{c}}$ and $D_{\text {tot }}$ (see Engelmann et al., 2016) of the cross and total channel, respectively, the volume linear depolarization ratio is derived without any further assumptions by

$\delta_{\mathrm{vol}}^{\lambda}(R)=\frac{V^{*}-\delta^{\lambda}(R)}{\delta^{\lambda}(R) D_{\mathrm{tot}}-V^{*} D_{\mathrm{c}}}$

with

$\delta^{\lambda}(R)=\frac{P_{\mathrm{c}}^{\lambda}(R)}{P_{\mathrm{tot}}^{\lambda}(R)}$,

where $P_{\mathrm{c}}^{\lambda}$ and ${ }^{\lambda} P_{\text {tot }}$ are the cross-polarized and total lidar signals, respectively. In the case of HOPE, depolarization measurements are available at $\lambda=532 \mathrm{~nm}$.

\subsection{Aerosol characterization}

The methodology to derive the lidar system parameters was based on $30 \mathrm{~min}$ averaged profiles of the particle backscatter coefficient, which are only available for specific atmospheric conditions. For the target characterization aimed at in this paper, $24 \mathrm{~h}$ measurements with $5 \mathrm{~min}$ resolution are analysed to characterize aerosols and clouds. The received signals of the backscattered light at 532 and $1064 \mathrm{~nm}$ and the depolarization ratio at $532 \mathrm{~nm}$ are used for this purpose. In the following, the methodology is introduced and then explained in detail in terms of a case study from HOPE.

\subsubsection{Obtaining aerosol products - extensive properties}

Since the molecular backscatter and extinction coefficients can be calculated from temperature and pressure profiles and the lidar system parameter can be estimated as described above, only the particle extinction coefficient, i.e. the transmission through the atmosphere, is left as an unknown in Eq. (1) to retrieve the particle backscatter coefficient. As a first guess for the particle backscatter coefficient, the particulate attenuation in the atmosphere is neglected, which re- 
duces Eq. (3) to

quasi* $^{*} \beta_{\mathrm{par}}^{\lambda}(R)=\beta_{\mathrm{att}}^{\lambda}(R) \exp \left\{2 \int_{0}^{R} \alpha_{\mathrm{mol}}^{\lambda}(r) \mathrm{d} r\right\}-\beta_{\mathrm{mol}}^{\lambda}(R)$.

To account for the incomplete overlap of the lidar system in lower heights, an overlap correction function is applied and height-independent backscattering below $500 \mathrm{~m}$ is assumed in analogy to the calculation of the lidar system parameter $C^{\lambda}$. The particle extinction coefficient is now estimated in analogy to the procedure during the calculation of $C^{\lambda}$ by multiplying quasi* $\beta_{\mathrm{par}}^{\lambda}(R)$ with a constant lidar ratio of $S_{\text {par }}=55$ sr:

${ }^{\text {quasi }} \alpha_{\text {par }}^{\lambda}(r)={ }^{\text {quasi* }} \beta_{\text {par }}^{\lambda}(R) S_{\text {par }}$.

As explained already in Sect. 3.1, the lidar ratio value used serves as a good compromise for lidar ratio values observed during HOPE and at other European continental sites. Finally, temporally high-resolved profiles of the so-called quasi-particle-backscatter coefficient defined as

$$
\begin{aligned}
& { }^{\text {quasi }} \beta_{\mathrm{par}}^{\lambda}(R)=\beta_{\mathrm{att}}^{\lambda}(R) \\
& \times \exp \left\{2 \int_{0}^{R}\left[\alpha_{\mathrm{mol}}^{\lambda}(r)+{ }^{\text {quasi }} \alpha_{\mathrm{par}}^{\lambda}(r)\right] \mathrm{d} r\right\}-\beta_{\mathrm{mol}}^{\lambda}(R) \\
& \approx \beta_{\mathrm{par}}^{\lambda}(R)
\end{aligned}
$$

can be calculated, which serve as best estimate for the particle backscatter coefficient $\beta_{\mathrm{par}}^{\lambda}(R)$ determined with the Raman or Klett method as demonstrated in Sect. 3.3.3. The quasi-particle-backscatter coefficient at 532 and $1064 \mathrm{~nm}$ is then used as the input for the particle characterization described below. An iterative approach for the determination of the particle extinction coefficient using the formulas above is not possible, because the solutions do not converge if the input lidar ratio is not exactly identical to the lidar ratio valid for the observed scatterers. If the input lidar ratio is higher than the atmospheric one, the extinction coefficient and thus also the backscatter coefficient is, in general, overestimated, and the procedure quickly approaches unstable solutions. On the other hand, if the lidar ratio input is too low, too small values that do not increase during the procedure are obtained. This behaviour is similar to the so-called Klett-Fernald forward iteration (Klett, 1981; Fernald, 1984), which also relies on a priori information of the lidar ratio and can be numerically unstable.

\subsubsection{Obtaining aerosol products - intensive properties}

With the calibration methods described above, a rough but temporally high-resolved aerosol characterization can be done by using the quasi-particle-backscatter coefficients and the volume depolarization ratio to obtain intensive aerosoltype specific quantities. From the quasi-particle-backscatter coefficients, the quasi-particle Angström exponent

quasi $_{\mathrm{a}}^{\stackrel{\lambda_{1} / \lambda_{2}}{\mathrm{par}}}=-\frac{\ln \left(\frac{{ }^{\text {quasi }} \beta_{\mathrm{par}}^{\lambda_{1}}}{\text { quasi }_{\mathrm{par}}^{\lambda_{2}}}\right)}{\ln \left(\frac{\lambda_{1}}{\lambda_{2}}\right)}$

is calculated for the wavelength pair $\lambda_{1}$ and $\lambda_{2}$, e.g. 532 and $1064 \mathrm{~nm}$, to obtain information on particle size.

The quasi-particle depolarization ratio defined as

${ }^{\text {quasi }} \delta_{\text {par }}^{\lambda}(R)=\left[\delta_{\mathrm{vol}}^{\lambda}(R)+1\right]$

$\times\left(\frac{\beta_{\text {mol }}^{\lambda}(R)\left[\delta_{\text {mol }}^{\lambda}-\delta_{\text {vol }}^{\lambda}(R)\right]}{\text { quasi } \beta_{\text {par }}^{\lambda}(R)\left[1+\delta_{\text {mol }}^{\lambda}\right]}+1\right)^{-1}-1$

is also an intensive property and used to obtain information about the particle shape. The molecular depolarization ratio $\delta_{\mathrm{mol}}^{\lambda}$ is calculated theoretically from the bandwidth of the interference filters (e.g. see Behrendt and Nakamura, 2002) and is 0.0053 at $532 \mathrm{~nm}$ in the case of Polly ${ }^{\mathrm{XT}}$ (Engelmann et al., 2016).

\subsubsection{Example observation: 22 April 2013}

To demonstrate the introduced quantities, the time-height cross sections of the four possible extensive (Fig. 3) and four possible intensive (Fig. 4) particle quantities of Polly $\mathrm{XT}$ are shown for 1 day of HOPE - the 22 April 2013.

The daily mean aerosol optical depth (AOD) was 0.34 at $500 \mathrm{~nm}$ wavelength on this day and thus was comparably high (monthly mean was 0.19 ). The atmospheric features are very well seen at 1064 and $532 \mathrm{~nm}$ while at $355 \mathrm{~nm}$ the atmospheric conditions are obviously not well represented, which will be explained later in detail. The 22 April 2013 started with a stratiform cloud with its base between 1.5 and $2.5 \mathrm{~km}$ which prevailed until 04:00 UTC. Below the cloud, inhomogeneous aerosol structures can be seen. The cloud is characterized by a high quasi-particle-backscatter coefficient at all wavelengths and a high volume depolarization ratio. After 04:00 UTC, a cloud-free nocturnal residual layer was observed. Note the layer structure, which indicates a slow descent of the lofted aerosol layer. At around 10:00 UTC (12:00 LT), the growth of the convective PBL could finally be observed. The PBL reached up to $2-2.5 \mathrm{~km}$ on this day. At 20:00 UTC, the nocturnal PBL began to form as can be seen below $1 \mathrm{~km}$ height in Fig. 3. No low-level or mid-level clouds were observed after 04:00 UTC, but cirrus at altitudes above $6 \mathrm{~km}$ (not shown) appeared after 13:00 UTC. From the temporal development of the volume depolarization ratio (Fig. 3, bottom), one can see that particles producing enhanced depolarization were mixed into the PBL from shortly after 12:00 UTC. A maximum of the quasi-particle depolarization ratio was observed at 16:30 UTC below $1.5 \mathrm{~km}$ height (Fig. 4, bottom). Obviously, non-spherical particles were mixed from the surface into the PBL as will be discussed further below. 

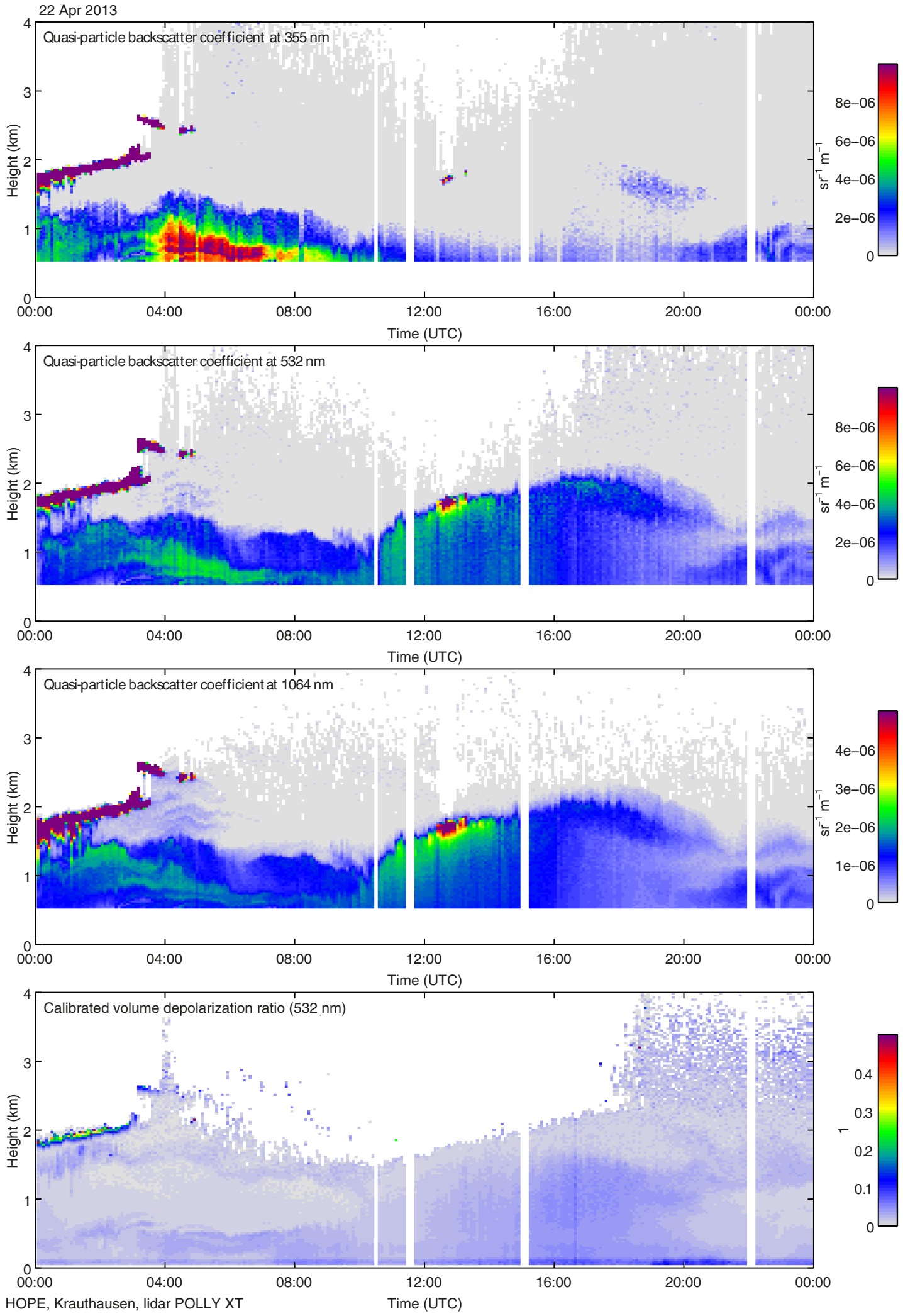

Figure 3. Polly observations at Krauthausen on 22 April 2013. Extensive properties from top to bottom: quasi-particle-backscatter coefficient at 355,532 , and $1064 \mathrm{~nm}$, and volume depolarization ratio at $532 \mathrm{~nm}$. 

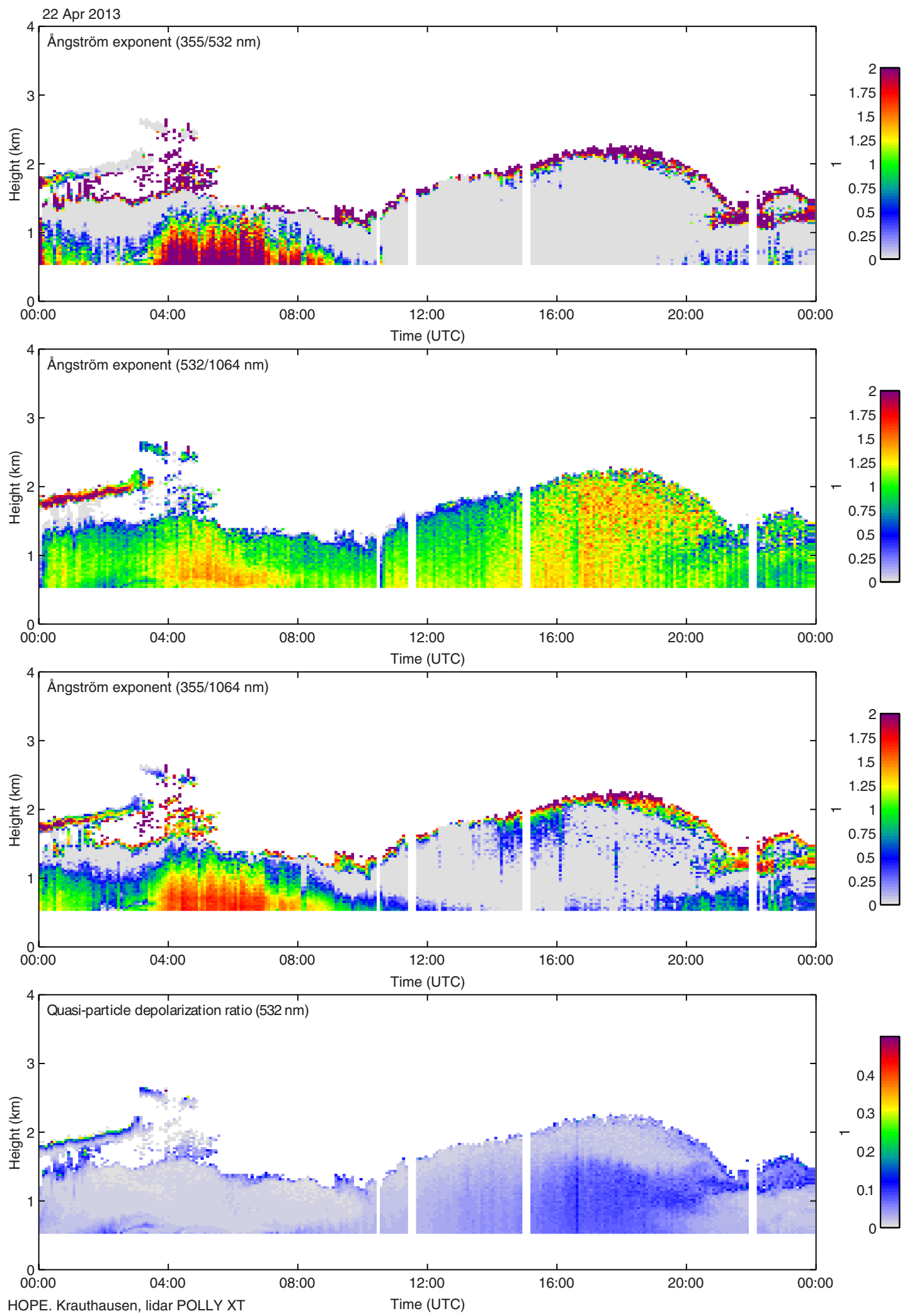

Figure 4. Polly observations at Krauthausen on 22 April 2013. Intensive properties from top to bottom: quasi-particle Ångström exponent for the wavelength pairs as indicated and quasi-particle depolarization ratio. 
The quasi-particle depolarization ratio is also enhanced at the lower cloud boundaries due to multiple scattering and/or because of falling ice crystals. The three quasi-particle Ångström exponents (Fig. 4) exhibit a very different behaviour showing that the Angström exponents incorporating the quasi-particle-backscatter coefficient at $355 \mathrm{~nm}$ are not representative. This is due to the corrections and assumptions made to estimate the particulate extinction and finally the quasi-particle-backscatter coefficient. As at $355 \mathrm{~nm}$ molecular backscattering is 80 (5) times higher than at $1064(532) \mathrm{nm}$, large uncertainties are introduced into the attenuation correction presented in Sect. 3.3 .1 when $355 \mathrm{~nm}$ signals are considered, even though the lidar system parameter is known with good accuracy. The partial negligence of particulate extinction in the first-guess profile (Eq. 6) and the subtraction of the molecular scattering contribution leads often to very large errors (as molecular backscattering is usually much stronger than particle backscattering at this wavelength) with even negative quasi-particle-backscatter coefficients. These effects are illustrated in Fig. 5 for a 30 min period of 22 April 2013. The particle backscatter coefficients determined with the Klett method, the attenuated backscatter coefficients, and the quasi-particle-backscatter coefficients are shown for the different wavelengths.

We have also considered other approaches to estimate the extinction at $355 \mathrm{~nm}$ for the calculation of the quasiparticle-backscatter coefficient (cp. Eq. 8), for example, by using the Ångström relationship (Ångström, 1964) to convert the $1064 \mathrm{~nm}$ extinction with an assumed a priori extinctionrelated Ångström exponent to the extinction coefficient profile at $355 \mathrm{~nm}$ similar to Eq. (9). Three different Ångström exponents were chosen which are representative for the HOPE campaign, i.e. 1.0, 1.4, and 2.0, to obtain the extinction at lower wavelengths from the extinction at $1064 \mathrm{~nm}$. This procedure is illustrated also in Fig. 5, where additionally the three backscatter coefficient profiles derived with this methodology are plotted. However, with that approach it was also found that the a priori choice of the extinction-related Ångström exponent is so crucial at $355 \mathrm{~nm}$ that it cannot be applied in an automatic retrieval (e.g. see profile derived with an Ångström exponent of 2.0 at $355 \mathrm{~nm}$ ). Closest to the particle backscatter coefficient at all wavelengths is the quasiparticle-backscatter coefficient derived with the methodology described in Sect. 3.3.1 (without the Ångström exponent assumption for extinction estimation). Taking into account the satisfying results at 1064 and $532 \mathrm{~nm}$ with this approach, one can conclude that the quasi-particle-backscatter coefficient is a better estimate than the attenuated backscatter coefficient for particle backscattering in the atmosphere.

This finding is also proved when comparing the different Ångström exponents as done in Fig. 6. Here, the Ångström exponents derived from the quasi-particle-backscatter coefficients at 532 and $1064 \mathrm{~nm}$ (deep yellow with stars) are very similar to the ones obtained from the particle backscatter coefficients derived with the Klett method (black, blue, and red, all close to 1.4 and height independent for the aerosol layer up to $2 \mathrm{~km}$ ). However, the Ångström exponents using the $355 \mathrm{~nm}$ quasi-particle-backscatter coefficients show already significant deviations (avocado green and purple) from the aforementioned value of 1.4. Even worse are the results when the attenuated backscatter coefficients are used (dark brown, orange, and magenta with circles), which shows again that this quantity cannot be applied for particle typing by using multiple wavelengths.

Consequently, we apply the quasi-particle-backscatter coefficients at 532 and $1064 \mathrm{~nm}$, which are straightforward to determine and which are close to the atmospheric truth; the corresponding quasi-particle Ångström exponent; and the quasi-particle depolarization ratio at $532 \mathrm{~nm}$ for the temporally high-resolution target categorization.

\section{Typing}

For the typing of atmospheric features, i.e. the optical dominant scatterer type, three extensive (quasi-particlebackscatter coefficient at 532 and $1064 \mathrm{~nm}$ and volume depolarization ratio) and two intensive properties (quasi-particle Ångström exponent and quasi-particle depolarization ratio) are available to detect aerosol and cloud layers and to distinguish between those two and classify subtypes. The lidaronly attempt is made to categorize aerosols and clouds concerning different types in analogy to the Cloudnet classification. In the following, the methodology is described followed by an intensive discussion concerning the applicability by means of example cases of HOPE.

\subsection{Typing methodology}

The complete typing procedure based on the quasi-particlebackscatter coefficients, depolarization ratios, and Ångström exponent profiles is illustrated in Fig. 7 and listed in Table 1.

The lidar-only classification consists of the following main classes: clean atmosphere, non-typed particles/low concentration, non-typed clouds, small spherical particles, large spherical particles, aerosol mixture, non-spherical particles, ice clouds, and liquid clouds. The "clean atmosphere" class represents a Rayleigh atmosphere where pure molecular scattering can be assumed. As the a priori information (i.e. the lidar ratio assumed) used to derive the quasi-particlebackscatter coefficient is valid for aerosol particles only; we do not aim to make a complete cloud classification. However, the quantities available for typing are mostly representative to identify the bases of ice clouds and liquid clouds. Attenuation correction at the base is not crucial, so the assumption of a wrong lidar ratio does not play a major role. However, we do not attempt to identify any particle classes above a liquid cloud as the attenuation correction will be corrupted. 


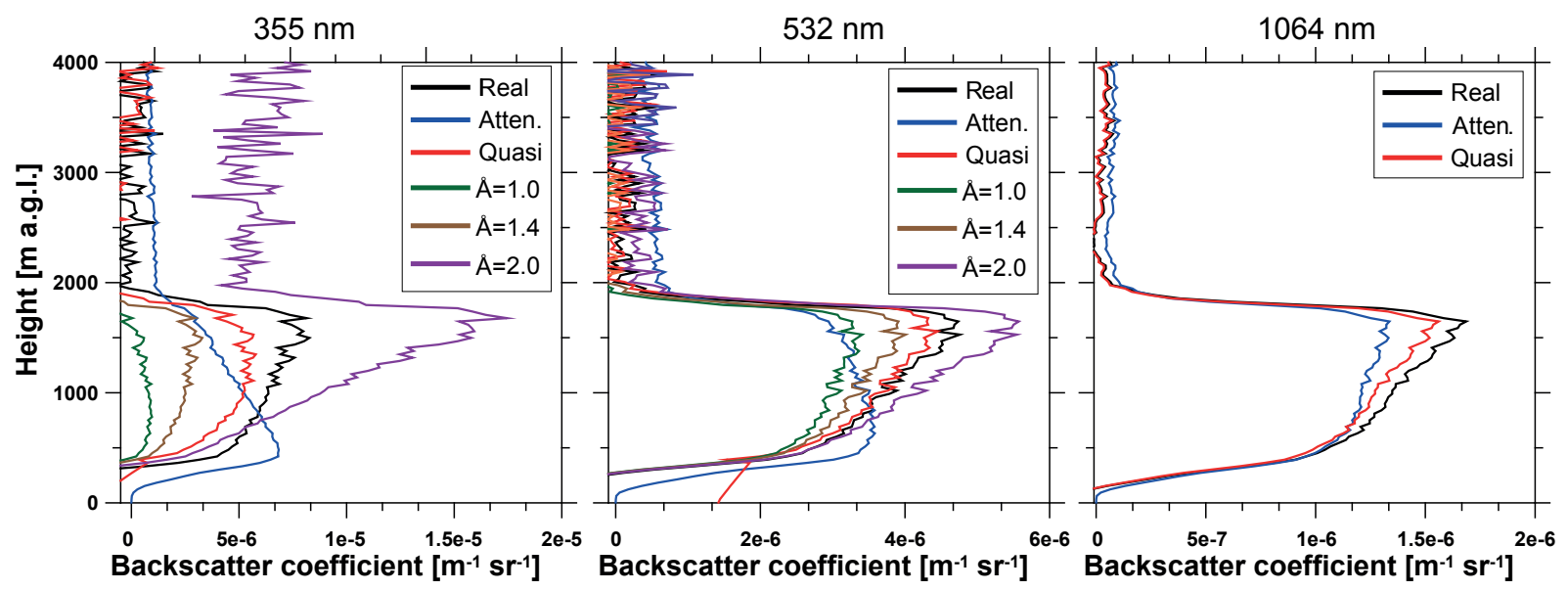

Figure 5. Comparison of the particle backscatter coefficient determined with the Klett method, the attenuated backscatter coefficient, and quasi-particle-backscatter coefficient for the three laser emission wavelengths on 22 April 2013, 14:20-14:50 UTC. Additionally, the quasiparticle-backscatter coefficient with a different approach for attenuation correction (extinction coefficient derived from the $1064 \mathrm{~nm}$ extinction coefficient with the Ångström relation) is plotted for Ångström exponents of $\AA=1.0,1.4$, and 2.0

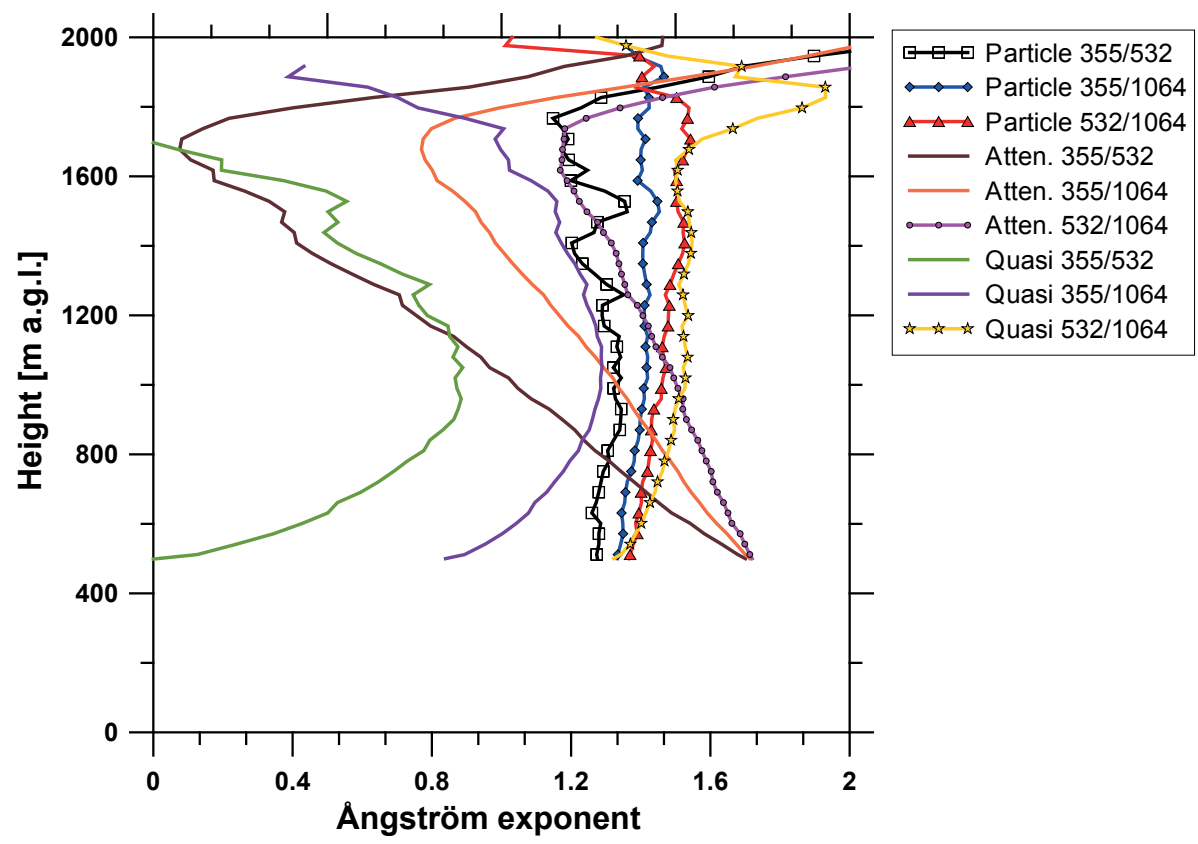

Figure 6. Comparison of Ångström exponents derived from the particle backscatter coefficients determined with the Klett method, the attenuated backscatter coefficients, and the quasi-particle-backscatter coefficients for 22 April 2013, 14:20-14:50 UTC. A five-bin vertical smoothing was applied.

Optical thick clouds are identified using the Cloudnet scheme for droplet finding (Illingworth et al., 2007; Hogan and O'Connor, 2004). As the lidar cannot penetrate liquid clouds, we cannot detect the cloud top, in contrast to Cloudnet, which uses the cloud radar information to gather this value. Therefore, the lidar target categorization will detect the cloud base and hydrometeors some tens of metres above the base. In principle within this scheme, clouds are detected if the quasi-particle-backscatter coefficient at $1064 \mathrm{~nm}$ is higher than $2 \times 10^{-5} \mathrm{~m}^{-1} \mathrm{sr}^{-1}$ and the signal decreases by a factor of 10 within $250 \mathrm{~m}$ above the maximum backscatter value. This algorithm is applied profile by profile, and the corresponding pixels above the threshold are flagged as non-typed cloud. Additionally, if the quasi-particle depolarization ratio is below 0.05 , the pixels are flagged as most-likely droplets, while, if the Angström exponent is also less than 0.5 , the pixels are flagged as droplets. The quasi-particle-backscatter coefficient threshold for clouds of 


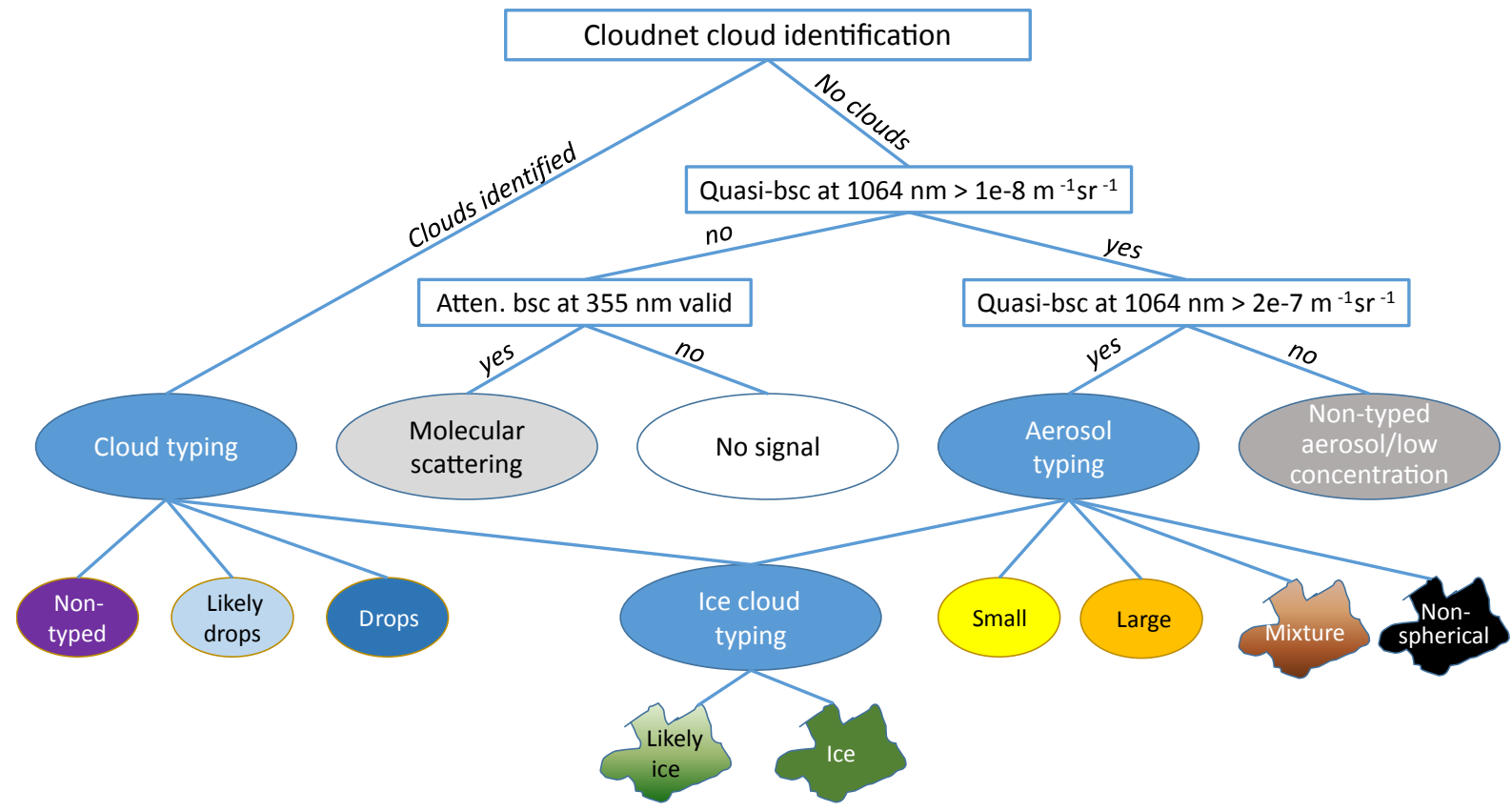

Figure 7. Schematic illustration of the typing procedure. Details in text and Table 1.

Table 1. Overview of particle typing. Criteria for the feature classes are given. Quasi-particle-backscatter coefficient values are given in $\mathrm{m}^{-1} \mathrm{sr}^{-1}$.

\begin{tabular}{|c|c|c|c|}
\hline \multicolumn{4}{|l|}{ Detected feature } \\
\hline Clean atmosphere & ${ }^{\text {quasi }} \beta_{\mathrm{par}}^{1064} \leq 1 \times 10^{-8}$ & & \\
\hline Non-typed particles/low concentration & quasi $\beta_{\mathrm{par}}^{1064}>1 \times 10^{-8}$ & & \\
\hline Aerosol: small & quasi $\beta_{\mathrm{par}}^{1064}>2 \times 10^{-7}$ & quasi $\delta_{\text {par }}<0.07$ & $\AA_{532-1064} \geq 0.75$ \\
\hline Aerosol: large, spherical & ${ }^{\text {quasi }} \beta_{\mathrm{par}}^{1064}>2 \times 10^{-7}$ & quasi $\delta_{\text {par }}<0.07$ & $\AA_{532-1064}<0.75$ \\
\hline Aerosol: mixture, partly non-spherical & quasi $\beta_{\text {par }}^{1064}>2 \times 10^{-7}$ & $0.07 \leq{ }^{\text {quasi }} \delta_{\text {par }}<0.20$ & \\
\hline Aerosol: large, non-spherical & ${ }^{\text {quasi }} \beta_{\text {par }}^{1064}>2 \times 10^{-7}$ & quasi $\delta_{\text {par }} \geq 0.20$ & \\
\hline Cloud: non-typed & Cloudnet algorithm & & \\
\hline Cloud: likely water droplets & Cloudnet algorithm & ${ }^{\text {quasi }} \delta_{\text {par }} \leq 0.05$ & \\
\hline Cloud: water droplets & Cloudnet algorithm & ${ }^{\text {quasi }} \delta_{\text {par }} \leq 0.05$ & $\AA_{532-1064} \leq 0.5$ \\
\hline Cloud: likely ice crystals & quasi $\beta_{\mathrm{par}}^{1064}>2 \times 10^{-7}$ & quasi $\delta_{\mathrm{vol}} \geq 0.30$ & quasi $\beta_{\mathrm{par}}^{532}>2 \times 10^{-7}$ \\
\hline Cloud: ice crystals & ${ }^{\text {quasi }} \beta_{\text {par }}^{1064}>2 \times 10^{-7}$ & ${ }^{\text {quasi }} \delta_{\text {par }} \geq 0.35$ & ${ }^{\text {quasi }} \beta_{\text {par }}^{532}>2 \times 10^{-7}$ \\
\hline
\end{tabular}

$2 \times 10^{-5} \mathrm{~m}^{-1} \mathrm{sr}^{-1}$ accounts for an extinction coefficient of about $3.6 \times 10^{-4} \mathrm{~m}^{-1}$ at all wavelengths (lidar ratio of $18 \mathrm{sr}$ for water droplets, Ångström exponent of 0 for large particles). According to the OPAC database (Hess et al., 1998), an extinction coefficient value of $3.6 \times 10^{-4} \mathrm{~m}^{-1}$ is higher than the values at $550 \mathrm{~nm}$ given for all aerosol types except for strong pollution. According to Liu et al. (2009), a threshold of $1 \times 10^{-5} \mathrm{~m}^{-1} \mathrm{sr}^{-1}$ at $1064 \mathrm{~nm}$ is well suited for the discrimination between cloud and aerosol because the largest overlap between the two types is between $4 \times 10^{-6}$ and $1 \times 10^{-5} \mathrm{~m}^{-1} \mathrm{sr}^{-1}$. The automatically retrieved particle backscatter coefficient profiles as presented in Baars et al. (2016) showed that during HOPE aerosol particle backscatter coefficients did not exceed $1 \times 10^{-5} \mathrm{~m}^{-1} \mathrm{sr}^{-1}$ (95\% per- centile maximum at $3 \times 10^{-6}$ ). Thus, we consider the chosen threshold as valid for the conditions during HOPE without overlapping of the categories. Visual inspection showed no misclassification of liquid clouds, which convinces us that the approach is valid for the detection of cloud bases. As soon as a liquid or non-typed cloud is classified, no other classes above are evaluated because of the risk of strong attenuation, multiple scattering, etc., which disturb the signals significantly as the lidar applied is designed for aerosol and not for cloud detection.

We classify the atmosphere as clean if the quasiparticle-backscatter coefficient at $1064 \mathrm{~nm}$ is less than $1 \times$ $10^{-8} \mathrm{~m}^{-1} \mathrm{sr}^{-1}$ and a valid signal of the $355 \mathrm{~nm}$ quasiparticle-backscatter coefficient $(\mathrm{SNR}>0.5$ at raw resolution 
of $30 \mathrm{~s}$ ) is present. This threshold yields a ratio of molecular to particle backscattering at $532(355) \mathrm{nm}$ higher than 60 (180) at sea level and thus is valid for a Rayleigh calibration by means of the Raman or Klett-Fernald lidar method. One future application of the target categorization presented herein might be to find appropriate regions for Rayleigh calibration, i.e. height regions of almost pure molecular scattering and sufficiently high SNR.

The threshold of $1 \times 10^{-8} \mathrm{~m}^{-1} \mathrm{sr}^{-1}$ is also well below the given range for aerosols according to Winker et al. (2009) for the CALIPSO classification. As the Polly ${ }^{\mathrm{XT}}$ systems have a higher detection sensitivity than CALIPSO, we cannot consider a higher threshold for clean atmosphere with Rayleigh scattering only. Anything above this threshold is first classified as non-typed particles, which could be aerosol or clouds.

Aerosol and ice clouds are typed for a quasi-particlebackscatter coefficient at $1064 \mathrm{~nm}$ greater than $2 \times$ $10^{-7} \mathrm{~m}^{-1} \mathrm{sr}^{-1}$. Everything below remains classified as "nontyped particles/low concentration". The threshold is equivalent to the one used in the CALIPSO feature mask $(5 \times$ $10^{-7} \mathrm{~m}^{-1} \mathrm{sr}^{-1}$ for the $532 \mathrm{~nm}$ attenuated backscatter coefficient, Omar et al., 2009) when considering an Ångström exponent of 1.4 as measured by AERONET on average during HOPE.

If the quasi-particle depolarization ratio is less than 0.07 and the quasi-particle Ångström exponent $\geq 0.75$, the scatterers are considered to be small particles. If the Ångström exponent is lower, it is supposed that large particles dominate the optical properties in the atmospheric volume. A mixture of non-spherical and spherical particles is considered when the particle depolarization ratio is between 0.07 and 0.2 , while above 0.2 the particles are categorized as large and non-spherical. The thresholds for the aerosol typing are chosen according to Amiridis et al. (2015) and Schwarz (2016), whose analyses of observations at several EARLINET stations show that large particles (marine, dust) have an Ångström exponent $(532-1064 \mathrm{~nm}$ ) less than 0.75 while smaller particle types (smoke, polluted continental, etc.) have an Ångström exponent (532-1064 nm) larger than 0.75. Pure Saharan dust is supposed to have a particle depolarization ratio at $532 \mathrm{~nm}$ of $31 \%$ (Tesche et al., 2009b; Ansmann et al., 2011), but lower ratios were also observed (e.g. around $28 \%$; Baars et al., 2016). Therefore, we consider particle depolarization ratios higher than $20 \%$ as mostly containing dust (or other non-spherical particles) and thus classify the scatterers as large, non-spherical particles. According to Tesche et al. (2009a), a $20 \%$ particle depolarization ratio corresponds to a dust fraction in terms of backscattering of more than twothirds. A particle depolarization ratio of $7 \%$, on the other hand, corresponds to a dust fraction of less than $20 \%$.

In contrast to other classification schemes (e.g. CALIPSO, Omar et al., 2009; HSRL, Burton et al., 2012), we do not categorize by aerosol origin (e.g. mineral dust, biomass burning smoke, etc.), but by physical features. For example, large, non-spherical particles are in most cases mineral dust ad- vected to the site but could also be volcanic ash, pollen, or local dust plumes. The interpretation is not possible without additional information and thus will be left to the user of the categorization. We want to focus on the physical properties as these are the quantities we can obtain with this lidar-only approach.

Ice crystals, as they occur in cirrus clouds or virgae, are identified by their highly depolarizing properties independent of the cloud identification or the aerosol typing and thus may overwrite these classes. As cirrus may be optically very thin, the same backscatter coefficient threshold as for aerosol is used to find ice crystals. The class "likely ice" is identified if the volume depolarization ratio (independent of quasi-particle-backscatter coefficient) is higher than $30 \%$. "Ice crystals" are identified if the particle depolarization ratio is higher than $35 \%$ and may overwrite the "likely ice" class. However, the identification of ice crystals is the most critical matter, as sometimes the depolarization information at $532 \mathrm{~nm}$ is not available due to the low SNR, whereas with the $1064 \mathrm{~nm}$ channel these particles can be detected. Thus, many ice crystals remain unclassified and are categorized as non-typed particles or clouds.

In the next section, we want to demonstrate the performance of the newly developed target categorization by means of three example cases.

\subsection{Examples for the aerosol categorization}

In the following, the observation days of 22,4 , and 18 April during HOPE are discussed by means of the lidar target categorization. These example cases represent a wide variety of different meteorological situations and are therefore well suited to demonstrate the capabilities of the newly developed lidar target categorization.

\subsubsection{April 2013}

Figure 8 shows the newly developed MWL classification scheme for the example day of 22 April 2013, which was already presented in Sect. 3.3.3. Several features were successfully detected: between 00:00 and 04:00 UTC, the cloud base of the liquid cloud was successfully identified. The base was categorized as "Cloud: likely water droplets" (light blue). Due to the required a priori assumptions for the quasi-particle-backscatter coefficients which are aiming at aerosols, the Ångström exponent was not below 0.5 and thus the "Cloud: water droplets" requirements were not fulfilled. Above the cloud base, the depolarization ratio is slightly enhanced due to multiple scattering (see Fig. 3, bottom) and thus the cloud is classified as a "non-typed cloud". Below the cloud, at the top of the PBL, large aerosol (orange) is identified above small aerosol particles (yellow) due to the low Ångström exponent (532/1064 nm, see Fig. 4). The growth of aerosol with increasing altitude within the PBL is most probably caused by hygroscopic growth. After 04:00 UTC, the 


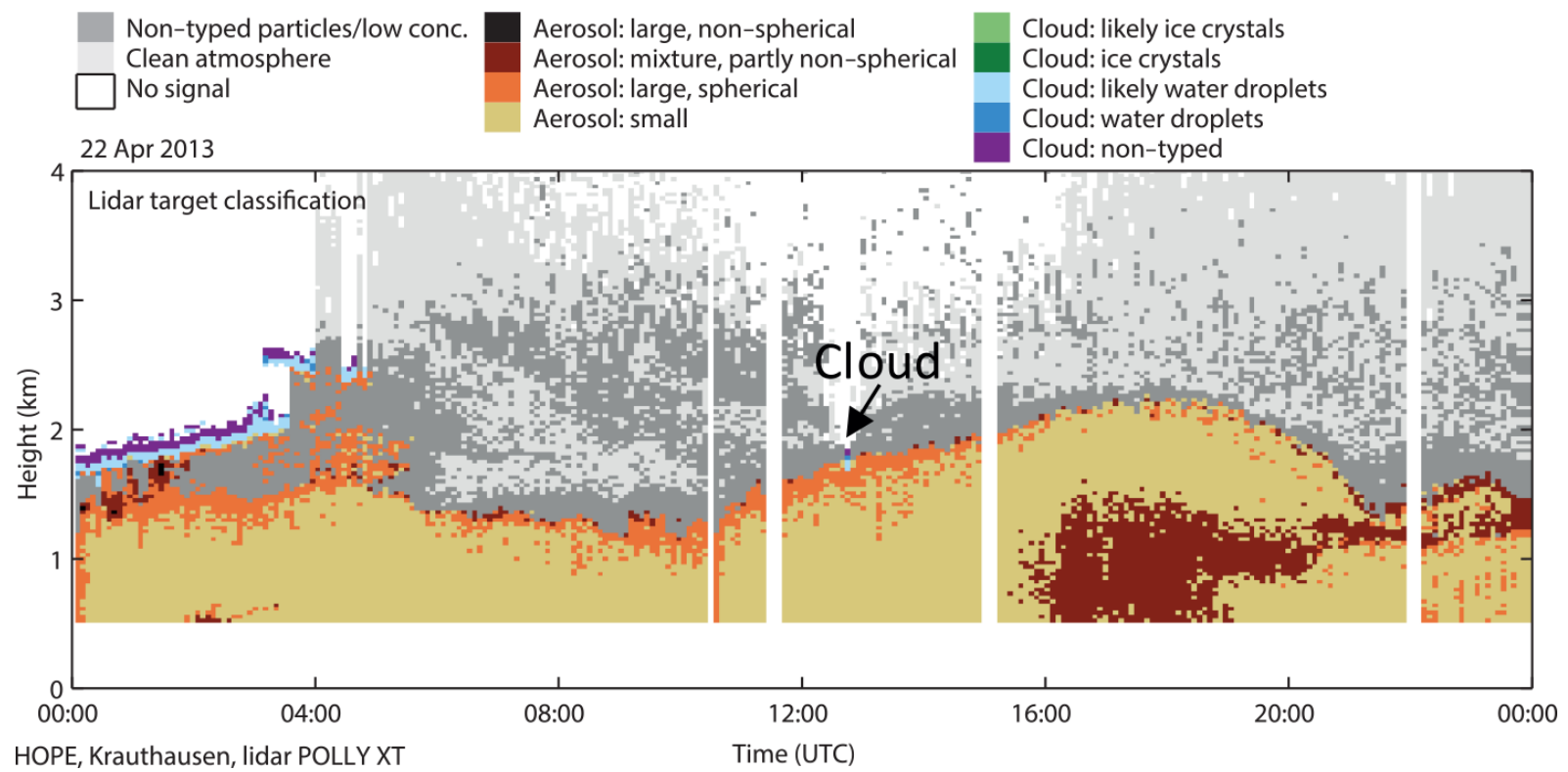

Figure 8. Lidar particle categorization for 22 April 2013.

cloud deck dissolved, and an aerosol layer with mostly small particles but large particles at the top remained the whole day. In addition, a small cumulus cloud was observed shortly past 12:00 UTC at the top of the convective PBL, remaining the only cloud at daytime on this day. The aerosol layer top and thus also the PBL top reached its maximum with $2.2 \mathrm{~km}$ at around 19:00 UTC before the aerosol layer starts to decay. We have to note that from the lidar target categorization the identification of the PBL, i.e. the mixing layer height, is not possible and needs additional information; therefore, we refer with the term PBL to the main aerosol layer which might have very often coincided with the mixing layer during daytime.

An interesting feature is the entrainment of partly nonspherical particles (brown) between 16:00 and 19:00 UTC from the surface. After 19:00 UTC, these non-spherical particles were detected close to the top of the nocturnal aerosol layer. The source of these non-spherical particles could be local dust (from open-pit mining close by, see Fig. 2 in Macke et al., 2016) and/or pollen from the local agricultural activity (e.g. see Fig. 1b in Maurer et al., 2016). Such entrainment from ground was very often observed in April at Krauthausen and needs to be investigated further in the future. Above the main aerosol layer, some aerosol, but in low concentration, is identified (dark grey), which means that these regions are not suitable for the so-called Rayleigh fit (Freudenthaler, 2009) needed for the Raman or Klett-Fernald lidar method for which one needs regions of molecular scattering only (light grey).

For comparison, Fig. 9 shows the standard Cloudnet classification (Illingworth et al., 2007) which is derived from cloud radar, microwave radiometer, and ceilometer obser- vations. This classification allows us to distinguish between the different cloud types and to detect aerosol. However, no discrimination between aerosol types is possible. At around $2 \mathrm{~km}$ between 00:00 and 03:00 UTC, a supercooled liquid layer was clearly observed (slightly above the lidar-detected cloud base). Below, ice crystals were identified, which turned into liquid at about $1.2 \mathrm{~km}$. According to temperature profiles retrieved from GDAS $1^{1}$ for the lidar location, the $0{ }^{\circ} \mathrm{C}$ altitude was $1.4 \mathrm{~km}$, confirming the findings. The identification of the liquid droplet layer by Cloudnet shows that the detected cloud features by lidar are certainly mostly liquid droplets and thus confirm the correct classification by the lidar categorization. The lidar, however, did not identify drops or ice below the cloud, most probably due to the low concentration of these hydrometeors for which the lidar is not sensitive. After 04:00 UTC, Cloudnet classifies aerosol only. The small cloud layer as observed with the MWL is also detected shortly past 12:00 UTC.

Finally, we can conclude the lidar-only target categorization works well and is in agreement with Cloudnet even though the different instrumentations allow the detection of different atmospheric features as intensively discussed in the next case study.

\subsubsection{April 2013}

A second example case to be discussed is 4 April 2013 at Krauthausen. The MWL target classification (top) and the Cloudnet ones (centre and bottom: LACROS and JOYCE) are shown in Fig. 10. JOYCE (Jülich ObservatorY for Cloud

\footnotetext{
${ }^{1}$ Global Data Assimilation System, https://www.ready.noaa. gov/gdas1.php
} 


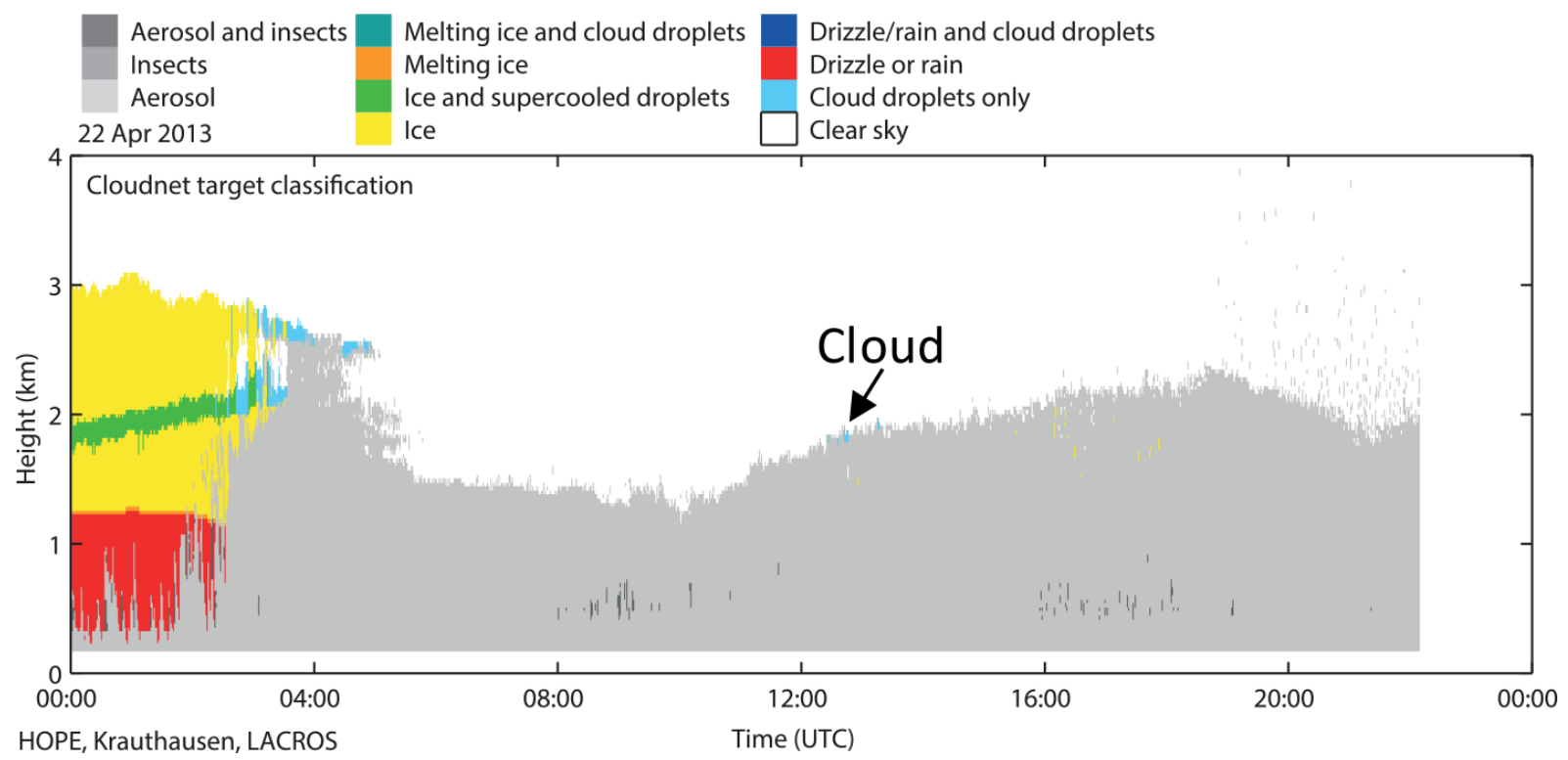

Figure 9. Cloudnet target categorization for 22 April 2013.

Evolution; $3 \mathrm{~km}$ away) data are shown because no data from Cloudnet are available for LACROS past 17:00 UTC due to maintenance work on the cloud radar. Nevertheless, the most interesting feature on this day is the overcast cloud condition between 03:00 and 10:00 UTC. During this time, the MWL classification detects very well the cloud base (cloud or likely cloud) and large aerosol below. The Cloudnet classification, however, detects the liquid cloud base as well, but it classifies below ice and super cooled droplets and/or ice not touching the ground. According to the temperature profile derived from the GDAS1 data set, a strong inversion was present between 1.8 and $2.2 \mathrm{~km}$ and temperatures were below $0^{\circ} \mathrm{C}$ throughout the troposphere. Thus, both classifications are reasonable, and one could suppose that the ice and drizzle detected by the radar led to evaporation which increased the relative humidity $(\mathrm{RH})$ in the aerosol layer and led to hygroscopic growth and finally, as detected, to large, spherical aerosol particles. As at the cloud base $100 \%$ RH can be considered, the particles just below the cloud experienced high $\mathrm{RH}$, and thus a strong particle growth has most likely led to increased scattering (e.g. Skupin et al., 2014).

This example shows the different sensitivity concerning particle size and thus the potential synergy between the lidarand radar-based classifications. While the lidar is more sensitive to the numerous but comparably small aerosol particles, the radar is most sensitive to the few but large precipitation particles. If we assume a Marshall-Palmer rain droplet number size distribution (Marshall and Palmer, 1948), we can estimate the light extinction of the drizzle in dependence of the rain rate as shown in Fig. 11. For low rain rates, which have occurred in the case of 4 April 2013 because no precipitation reached the ground, extinction coefficients well below typical aerosol values are calculated. Aerosol extinction in the
PBL was about 150 to $200 \mathrm{Mm}^{-1}$ throughout the observation time in the case presented here. At a height of $1.5 \mathrm{~km}$, which is $250 \mathrm{~m}$ below the cloud base, extinction coefficients of about $100 \mathrm{Mm}^{-1}$ were observed at 04:00 UTC. When no clouds were present at 01:00 UTC, they were 35 to $50 \mathrm{Mm}^{-1}$ at this height. Thus, if one considers hygroscopic growth, one can conclude that the lidar signal was dominated by aerosol instead of the few drizzle droplets even though they also contributed to the lidar return. On the other hand, as the radar is sensitive to the sixth power of the diameter of the scatterers (while the lidar is to the power of 2), it is sensitive to the few but large precipitation droplets. Therefore, the Cloudnet classification defines the region of interest to contain ice and supercooled drops and ice only - putting the priority on the cloud-sensitive radar observations. Given the added value of the multiwavelength lidar aerosol classification, we can however conclude that between 03:00 and 10:00 UTC all detected features, i.e. large, spherical aerosol particles and ice and supercooled drops, were present simultaneously, even though the full instrument synergy of the instruments presented here is still a current research topic.

Past 11:00 UTC, another cloud with its base at around $1 \mathrm{~km}$ was detected at the top of the growing PBL. Again, the cloud base is identified with lidar at the height at which Cloudnet identifies cloud droplets only. Above and below the cloud base, Cloudnet classifies ice crystals, which cannot be verified with the MWL target categorization. There, mostly small, but also some large, spherical particles close to the cloud base are identified. Above the cloud base, no valid lidar signal is available.

Past 16:00 UTC, the lidar detected ice clouds from 2.5 to $6 \mathrm{~km}$ height, which was observed with Cloudnet instrumentation too. Cloudnet is able to detect the ice clouds already 


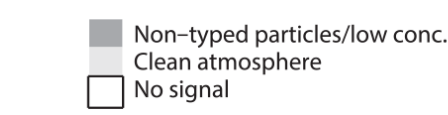

124 Apr 2013

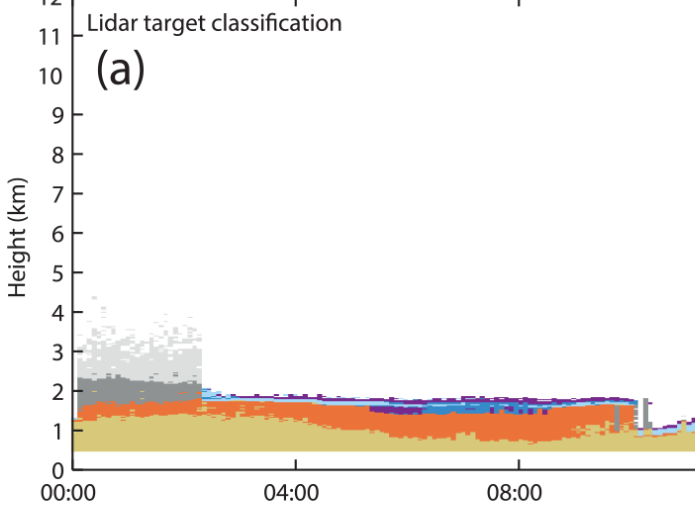

HOPE, Krauthausen, lidar POLLY XT
Aerosol: large, non-spherical Aerosol: mixture, partly non-spherical Aerosol: large, spherical Aerosol: small
Cloud: likely ice crystals

Cloud: ice crystals

Cloud: likely water droplets

Cloud: water droplets

Cloud: non-typed

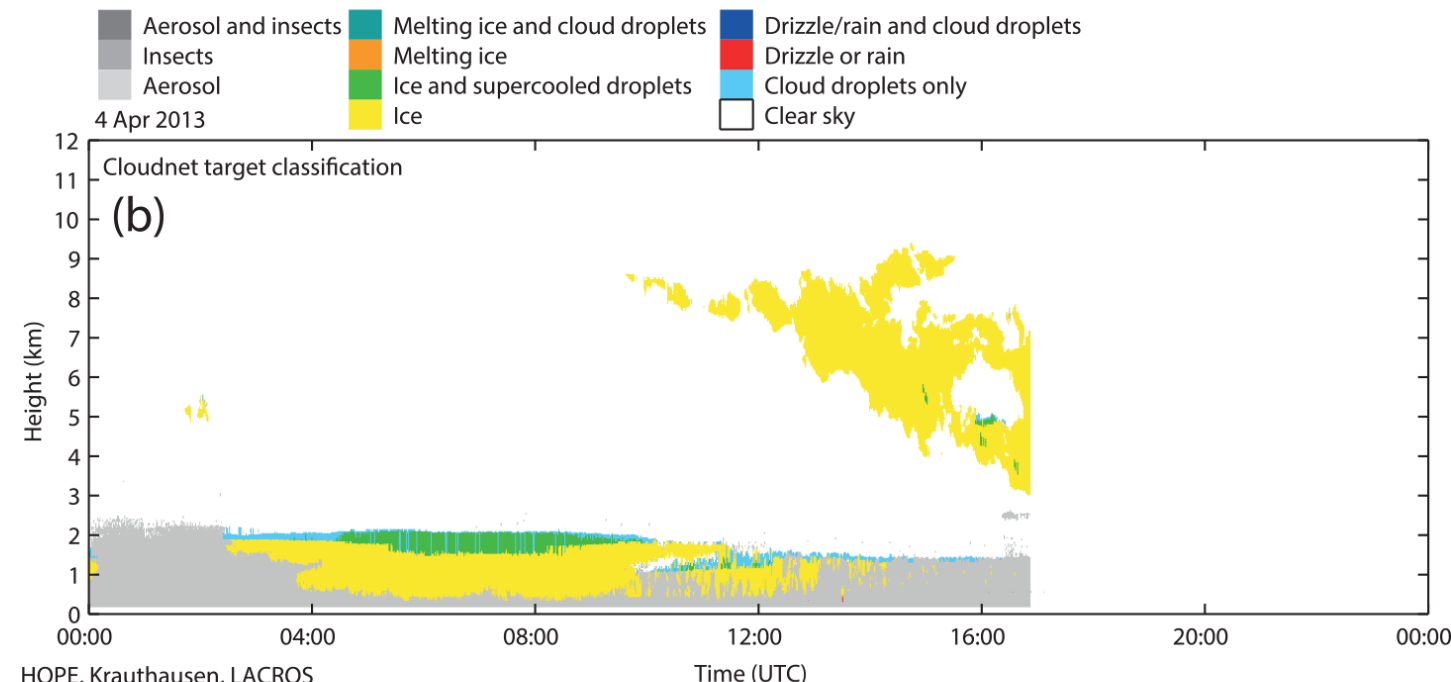

HOPE, Krauthausen, LACROS

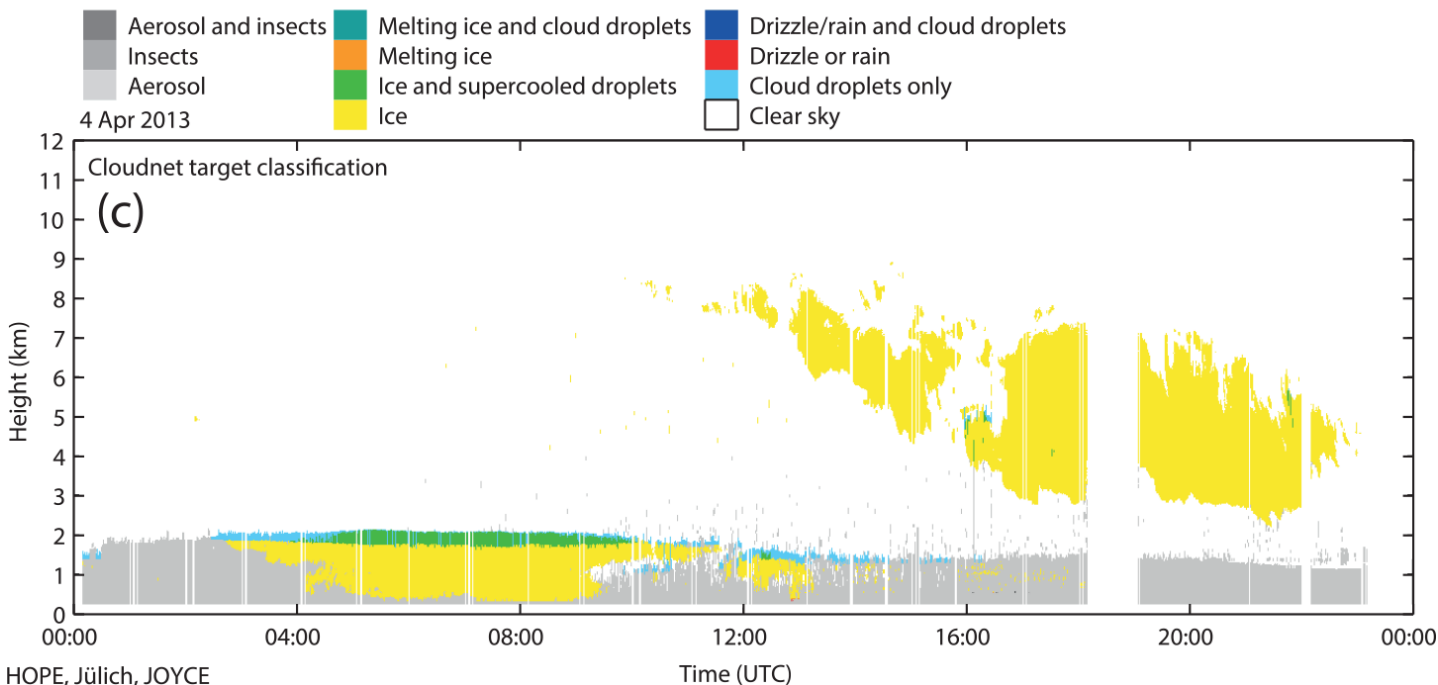

Figure 10. Lidar particle categorization (a) and Cloudnet target categorization (b and c) for 4 April 2013 at Krauthausen and Jülich. 


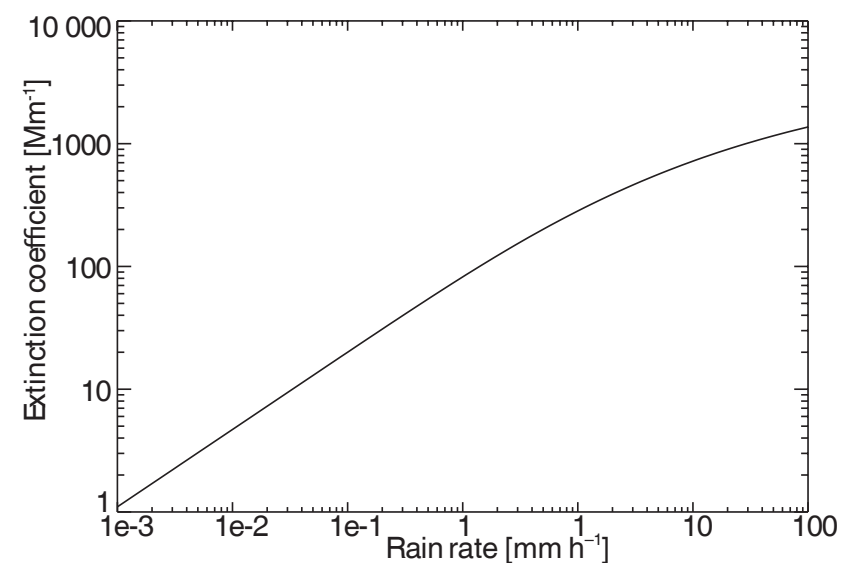

Figure 11. Simulated light extinction coefficient for drizzle in dependence of rain rate.

before at altitudes up to $9 \mathrm{~km}$, which is not possible with the MWL during the low-level-cloud-deck period. Interestingly, during the period past 16:00 UTC, a lofted aerosol layer was found below the ice cloud between 2 and $3 \mathrm{~km}$ classified mostly as spherical particles. Below, in the transition zone to the PBL, non-spherical particles were identified because of an increased depolarization ratio. In the PBL itself, small, spherical particles were observed. The Cloudnet observations from JOYCE only $3 \mathrm{~km}$ away, however, gave no indication of ice crystals at this altitude, so we can conclude that the nonspherical particles were advected towards the site.

Interestingly, at around 17:00 UTC, large, spherical particles are directly classified below/within the ice cloud at around $3.5 \mathrm{~km}$ because of low depolarization values. We can only speculate that due to evaporation of ice crystals, residual aerosol might have grown. Unfortunately, the radar at LACROS was not in operation to investigate this feature in more detail.

As can be seen as well in Fig. 10a, ice crystals are often classified correctly but sometimes remain unclassified or are even falsely classified as aerosol. The reason for the nonclassification of ice crystals is mostly the lack of depolarization information at $532 \mathrm{~nm}$ while the $1064 \mathrm{~nm}$ channel is able to detect particles especially at high altitudes at which the SNR of the $532 \mathrm{~nm}$ channels is too low. This occurs, e.g. for the thin ice cloud at about $10 \mathrm{~km}$ past 21:30 UTC.

The frequency of occurrence of misclassification of ice crystals as aerosol is increasing with increasing penetration depth of the ice clouds as can be seen in Fig. 10a past 16:00 UTC in the height range of 4-7 km. The reason for that false classification is the used a priori information aiming on aerosol (i.e. the lidar ratio and Ångström exponent). This leads to a wrong attenuation correction and thus to wrong quasi-particle-backscatter coefficient and quasi-particle depolarization ratio values above the cloud base. Furthermore, multiple scattering at the large cloud hydrometeors leads to an additional underestimation of the light attenuation (see
Seifert et al., 2007; Kienast-Sjögren et al., 2016, or Gouveia et al., 2017). For that reason, the current lidar stand-alone approach is trustworthy only at cloud bases and a few tens of metres above, depending on the cloud optical thickness. Nevertheless, in the case of ice clouds, the classification is also performed above the cloud base as the cloud optical thickness is usually low and thus false classification is comparably rare, as seen in Fig. 10a. However, we think the cloud classification can be significantly improved, when the lidaronly categorization is combined with the Cloudnet one, as explained in the outlook, because the use of cloud radar information will allow setting different a priori information for the clouds.

This case study also shows that, under conditions of lowlevel clouds, atmospheric features can be identified by MWL with the newly developed methodology, which is not easily possible with the traditional Raman or Klett-Fernald lidar methods.

\subsubsection{April 2013}

The third example day, 18 April 2013, is shown in Fig. 12.

This day is characterized by strong westerly winds with wind gusts up to $16 \mathrm{~m} \mathrm{~s}^{-1}$ as it was found from Doppler lidar observations. On this day, a mixture with non-spherical aerosol in the lowermost boundary layer was observed almost continuously, except for the period of cloud occurrence between 05:00 and 07:00 UTC. This liquid cloud is identified with MWL and Cloudnet in good agreement. The MWL classification detects an optically thin lofted aerosol layer between 2 and $3.5 \mathrm{~km}$ height after the low cloud layer disappeared at around 07:00 UTC. Cloudnet did not detect this aerosol layer. At the top of this layer, a cloud formed shortly past 08:00 UTC. Both clouds are identified to be pure liquid by both algorithms. Shallow boundary layer clouds were observed occasionally past 12:00 UTC.

Due to the strong westerly winds, we conclude that the observed non-spherical particles in the PBL originate from the open-pit mine of Inden (see Fig. 2 in Macke et al., 2016) west of our measurement location. Most of these particles remained below $1 \mathrm{~km}$ at the lidar site (except during the growing phase of the PBL from 10:00 to 12:00 UTC). This is an indication that the particles were just entrained into the PBL and had not had the time to be transported to the top of the PBL yet. Another reason could be that the particles were of much larger size than typical aeolian dust and thus sediment much more rapidly after their emission than other particle types. Visual inspection of the pit mine of Inden, $1.5 \mathrm{~km}$ west of the LACROS site, proved strong dust emissions as shown in Fig. 13.

After 23:00 UTC, a shallow convective cloud system whose precipitation (first ice than drizzle) did not touch the ground at the LACROS site (see Cloudnet categorization in Fig. 12) was observed. The MWL target categorization also detects the cloud but, as already discussed in the previous 

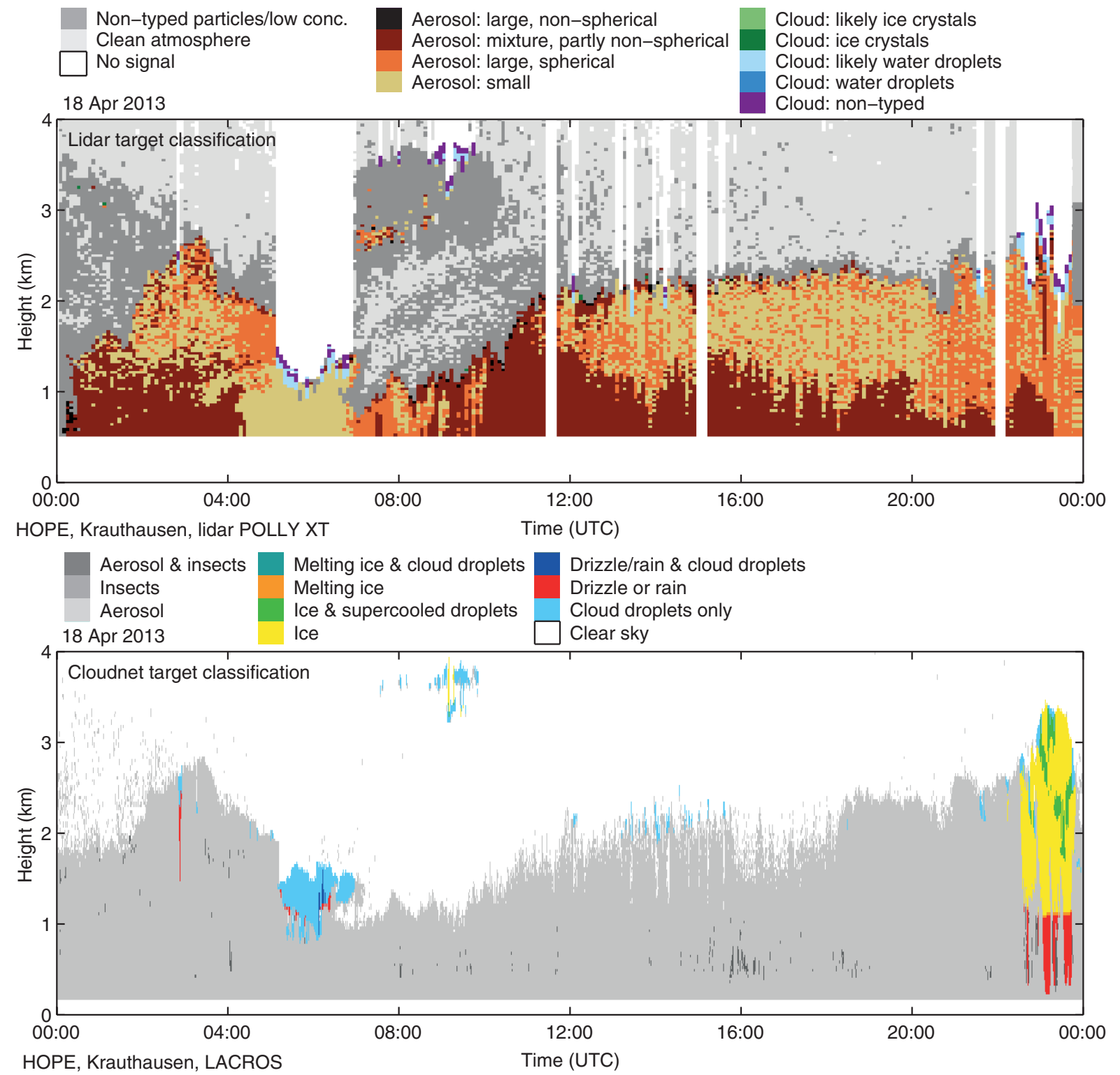

Figure 12. Lidar particle categorization (top) and Cloudnet target categorization (bottom) for 18 April 2013.

example case, does not obviously resolve the drizzle and ice but identifies large aerosol particles, which might again have been influenced by hygroscopic growth due to precipitation evaporation.

\section{HOPE}

In this section, an overview of the aerosol conditions during entire HOPE is provided. The MWL Polly $\mathrm{IfT}$ was routinely operating at Krauthausen from 2 April 2013 to 31 May 2013. Thus, 2 full months of a spring season could be covered. An overview of the observations of the full campaign is given in the Appendix in Fig. A1 (April) and Fig. A2 (May) in terms of the quasi-particle-backscatter coefficients at 532 and $1064 \mathrm{~nm}$ (extensive properties), the quasi-particle Ångström exponent (532-1064 nm), and the quasi-particle depolarization ratio (intensive properties) as used for the categorization. As described in Macke et al. (2016), the weather conditions during HOPE varied from periods with several warm and cold front passages interrupted by a few high-pressure systems with high-level cirrus clouds at the beginning of the campaign to more low-level convective cloud conditions later on.

Continuous MWL observations were available during the entire period with the exceptions of some short interruptions due to maintenance. During days of almost only precipitation (e.g. 16 May 2013), lidar observations are only sporadically 


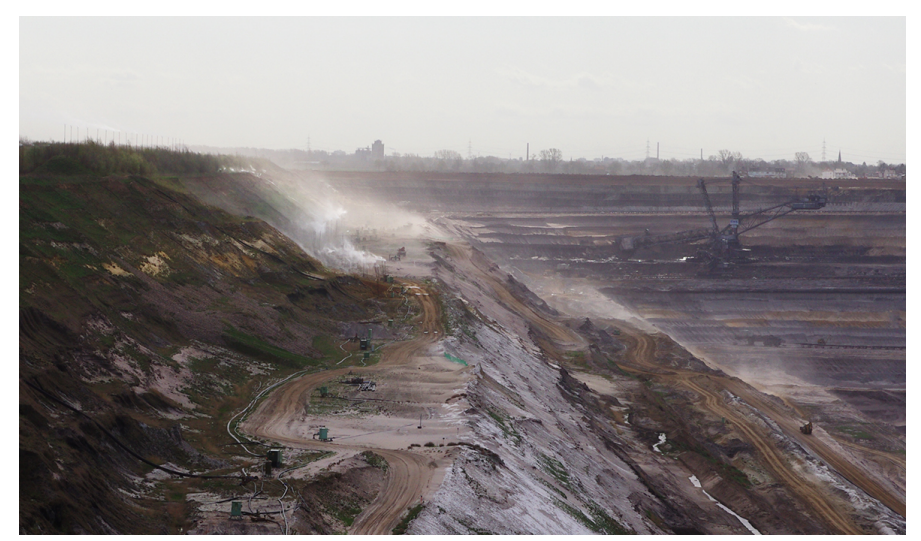

Figure 13. Photograph of the easterly border of the open-pit mine of Inden on 18 April 2013. Strong dust emissions were observed. The LACROS site was located $1.5 \mathrm{~km}$ east (i.e. downwind) of the pit.

available as the system stops measurements during precipitation events. Thus, calibrated lidar signals and the corresponding Ångström exponents and depolarization ratios are available for most of the time of favourable weather conditions and allow the typing of the particles according to the scheme described above.

The corresponding lidar target categorization for the entire HOPE campaign aiming on aerosol discrimination is shown in Fig. 14 together with the respective Cloudnet classification. The lidar target categorization reveals that aerosol was usually located from the ground up to $2 \mathrm{~km}$ height. Nontyped particles and low aerosol concentration were typically detected up to higher altitudes $(4-5 \mathrm{~km})$ showing that these regions are not appropriate for the Rayleigh fit procedure as already described above. Furthermore, it can be seen that the spring of 2013 at Krauthausen was dominated by low-level clouds and cirrus. Only on a few days clear sky conditions were observed. Comparing to the Cloudnet target categorization, it is confirmed that April and May was often dominated by deep clouds covering almost the whole troposphere. The lidar target categorization by definition only identifies the cloud bottoms in these cases, but this in good agreement with Cloudnet.

Interestingly, the intrusion of non-spherical particles was observed several times in the lowest $2 \mathrm{~km}$ until beginning of May (see lidar target categorization in Fig. 14). We can only speculate that this might be local dust from open-pit mining, as intensively discussed for the 18 April case study, or pollen. After 10 May 2013, low-level clouds together with precipitation prevailed (see also Cloudnet target categorization), and thus it is reasonable that the local dust was too wet to be entrained into the air and/or the pollen season was over. These observations might be an interesting topic for future studies focusing on local aerosol emissions.

Furthermore, one sees that during HOPE the majority of the aerosol in the PBL was classified as small aerosol, as we would expect for an industrial and highly populated area.
However, large aerosol was also observed occasionally, but mostly at the top of the PBL, indicating the importance of hygroscopic growth. Comparing again to Cloudnet, one sees that drizzle is often observed with radar while the lidar still detects aerosol. This interesting feature, discussed already for the presented case studies, was observed frequently and demonstrates the different sensitivity of the different instruments. Furthermore, it is found that Cloudnet does not detect as much aerosol with low concentrations due to the use of the ceilometer, which is not as powerful as the MWL.

To give an overview of the aerosol and also partly the cloud conditions during HOPE, a statistic of the classified scatterers for the entire troposphere for HOPE is shown in Fig. 15. Concerning typed aerosol (Fig. 15, top, left), the majority of the particles were classified as small aerosol (twothirds). Large, spherical particles were observed $20 \%$ of the time, while a mixture of non-spherical and spherical particles was observed in $9 \%$ and large, non-spherical particles only in $3 \%$ of the analysed pixels. As already discussed, these particles were mostly mixed from the ground into the atmosphere. Only on a few of the days, thin, lofted layers of Saharan dust were observed.

If one also takes into account the "non-typed particles/low concentration" class (Fig. 15, left, bottom) one sees that surprisingly $42 \%$ of the particles are non-typed or of low concentration. But one has to take into account that this particle class can inherit every scatterer type (i.e., all types of clouds and aerosol) and that very low aerosol concentrations were almost always present above the PBL. Due to the conservative approach chosen, particles are only typed if enough information is available. Thus, often the $1064 \mathrm{~nm}$ channel, which is least sensitive for molecular scattering, detects particles while the other channels have a too-low SNR to be used for particle typing, which leads to a large number of pixels being classified as non-typed aerosol particles. However, the information given by this category is still very useful, as it makes clear that molecules are not the only ones that con- 

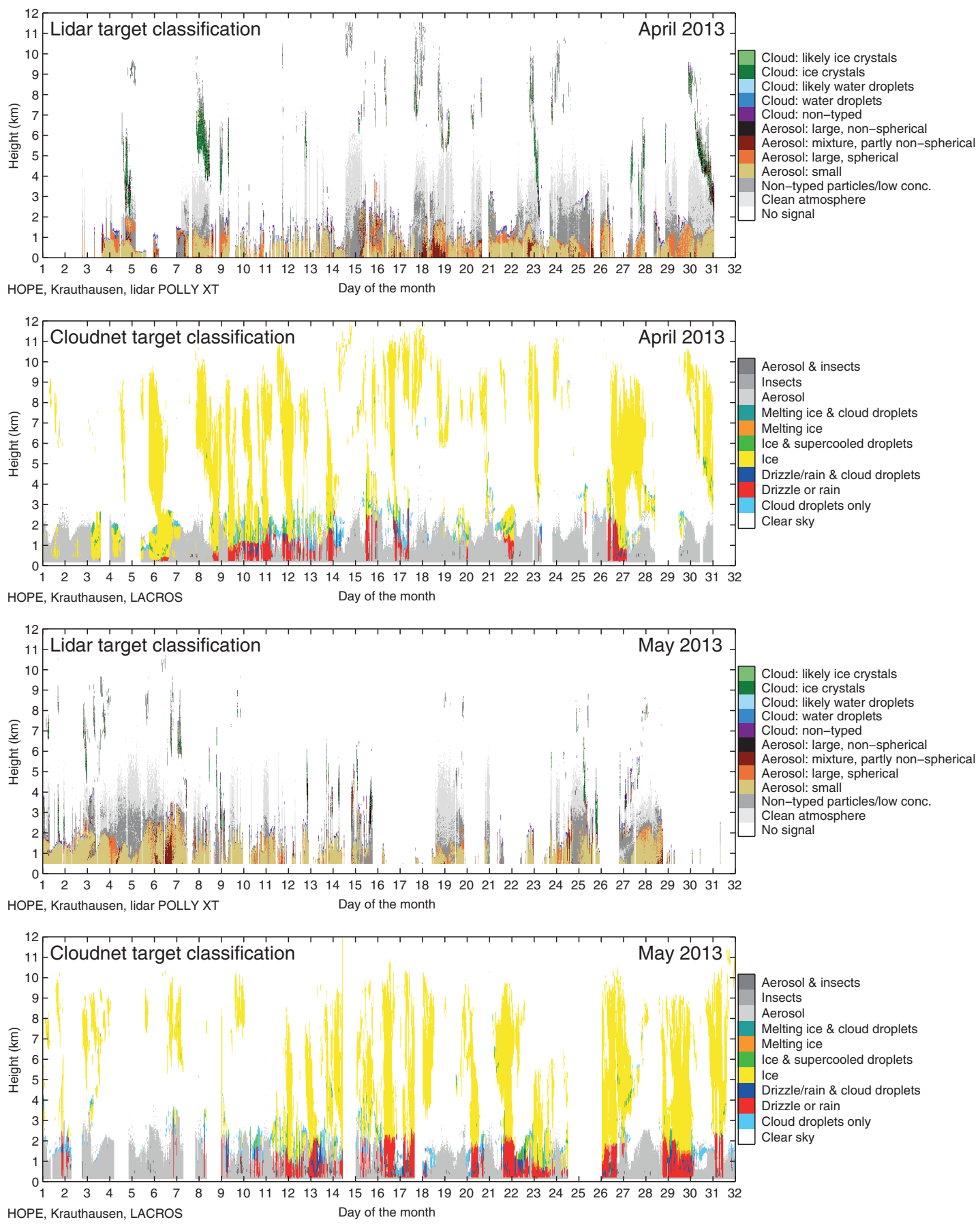

Figure 14. Lidar particle categorization and Cloudnet categorization for April (top) and May (bottom) 2013.

tribute to the light scattering, which is important when the target classification will be used for the determination of suitable calibration periods and regions with negligible aerosol scattering.

For the clouds identified during HOPE, a different picture was obtained (Fig. 15, top, right). Here, the "likely ice cloud" class is the dominant type, with $46 \%$. Due to the assump- tion made above aiming on aerosols (lidar ratio), the quasiparticle depolarization ratio is underestimated in cirrus and thus does not often exceed $35 \%$. Therefore, the clearly identified ice clouds make only a fraction of $6 \%$. However, we have to repeat that we do not aim at classifying clouds as we focus on aerosol, and the cloud information might be used only as a hint for the type of clouds for which further inves- 
(a)

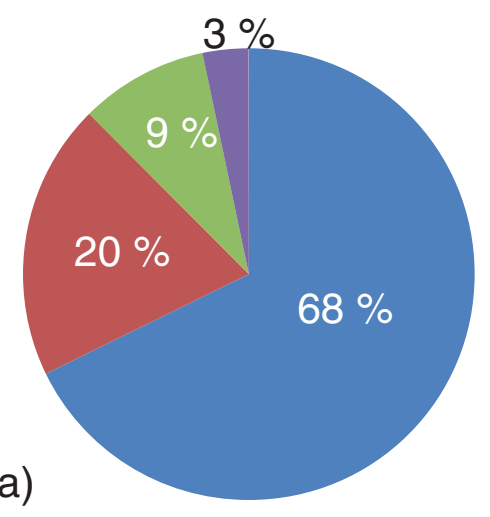

(b)

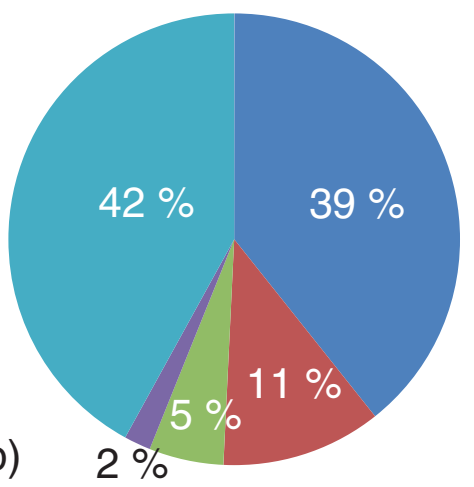

Aerosol: small

- Aerosol: large, spherical

Aerosol: mixture, partly non-spherical

Aerosol: large, nonspherical

$\mathrm{N}=387894$

Aerosol: small

n Aerosol: large, spherical

Aerosol: mixture, partly non-spherical

Aerosol: large, nonspherical

- Non-typed particles/low concentration

$$
N=668764
$$

(c)

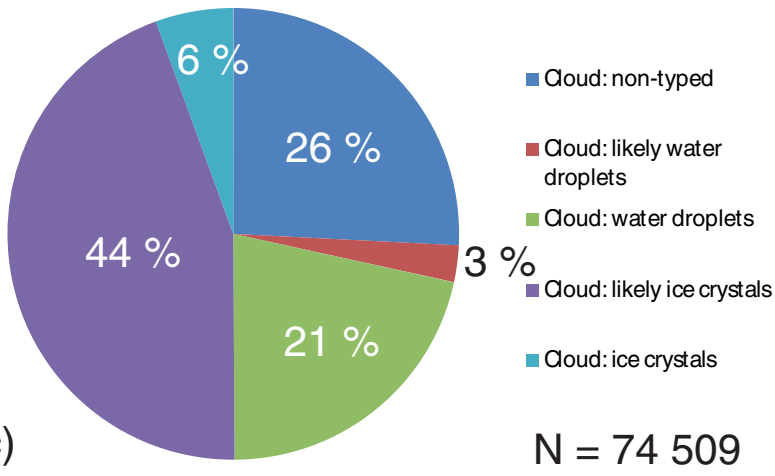

(d)

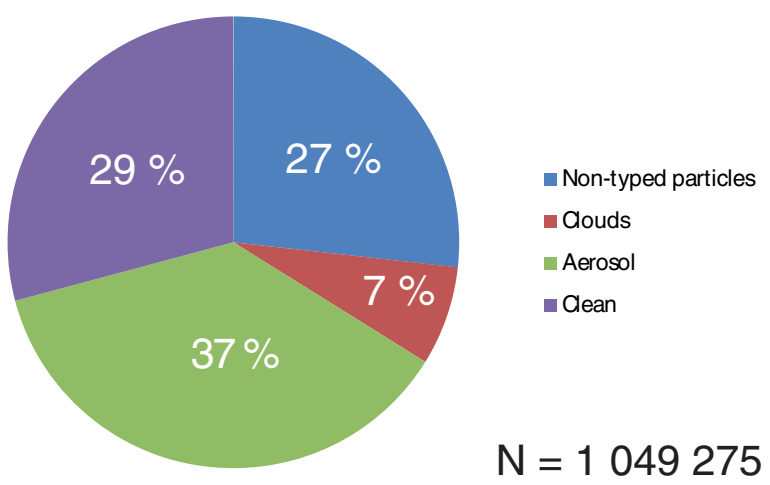

Figure 15. Statistics on particle categorization for the entire HOPE campaign: (a) for all typed aerosol particles, (b) typed aerosol and non-typed particles, (c) cloud particles, and (d) all typed pixels.

tigations are necessary. Water droplets are typed in $21 \%$ of all cases and likely liquid clouds only three percent of the time. Non-typed clouds amount to $26 \%$ of all cloud classes. We have to repeat that this cloud statistic is biased as the lidar can penetrate liquid clouds only by a few tens of metres. Above a detected liquid cloud, no typing is performed. In turn, the lidar can often penetrate cirrus clouds, and thus, in contrast to liquid clouds, ice crystals can also be detected well above the cloud base.

Altogether during the HOPE campaign, more than 1 million pixels in the troposphere of $30 \mathrm{~m}$ vertical and $5 \mathrm{~min}$ temporal resolution could be analysed. From these pixels, clean (i.e. molecular scattering dominating) atmosphere was observed in $29 \%$, clouds in only $7 \%$, aerosol in about $37 \%$, and "non-typed particles/low concentration" in $27 \%$ of the analysed and feature-classified pixels (Fig. 15, bottom, right).

\section{Conclusions}

In this work, we have used absolutely calibrated lidar signals to categorize primary aerosol but also clouds in high temporal and spatial resolution. Two months of 24/7 observations from the multiwavelength-Raman-polarization lidar Polly $\mathrm{IfT}$ during the HOPE campaign have been analysed for that purpose. We have used the well-established Cloudnet framework to develop a lidar stand-alone classification. The Cloudnet equipment was operated continuously directly next to the lidar and has been used for comparison.

Automatically derived particle backscatter coefficient profiles (Baars et al., 2016) in low temporal resolution (30 min) have been used to calibrate the lidar signals. A daily mean lidar calibration parameter was derived with an accuracy better than $20 \%$. From these calibrated lidar signals, new atmospheric parameters in temporally high resolution (quasiparticle-backscatter coefficient) which require a priori information (assumptions) for attenuation correction have been developed. It was found that the newly developed procedure works well at 532 and $1064 \mathrm{~nm}$, but deviations from the particle backscatter coefficients can be strong at $355 \mathrm{~nm}$ when the a priori information is not perfect. As a consequence for the particle typing, the quasi-particle coefficients at 532 and $1064 \mathrm{~nm}$, its corresponding Ångström exponent, and the linear depolarization ratio at $532 \mathrm{~nm}$ are used for the classification.

By using thresholds obtained from multiyear, multisite EARLINET measurements, four aerosol classes (small; large, spherical; large, non-spherical; mixed, partly nonspherical) are defined. Thus, particles were classified by their 
physical features (shape and size) instead of by source as, for example, the well-known CALIPSO typing does. For source definition, additional information is needed, which has been out of the scope of this development, which has focused on a lidar stand-alone tool.

The bases of optical thick clouds (liquid droplets) can be identified using the Cloudnet approach applied to the MWL. Cirrus clouds/ice are identified by its highly depolarizing features. Furthermore, regions dominated by molecular scattering and regions of non-typed particles/low aerosol concentration are identified with the target categorization. The detection of molecular regions can be very useful for lidar calibration in the atmosphere.

By discussing three $24 \mathrm{~h}$ case studies, it was shown that the aerosol discrimination is very feasible and informative and gives a good complement to the Cloudnet target categorization. By analysing the entire HOPE campaign, almost 1 million pixel $(5 \mathrm{~min}, 30 \mathrm{~m})$ could be successfully classified with the newly developed tool from the 2-month data set. We found that the majority of the aerosol trapped in the PBL were small particles as expected for a heavily populated and industrialized area. Large, spherical aerosol was found mostly at the top of the PBL and close to cloud bases, indicating the importance of hygroscopic growth of the particles at high relative humidity. Interestingly, it was found that on several days non-spherical particles were mixed from the ground into the atmosphere. The origin of these particles remains unclear and needs further research. Lofted layers of Saharan dust as it is typical for spring in Germany were observed only sporadically and with low AOD during the investigated time frame of the HOPE campaign in spring 2013. Non-typed aerosol with low concentrations was found often above the PBL up to heights of about $4 \mathrm{~km}$. Cloudnet was not able to identify these optically thin particle layers due to the lower sensitivity of the used ceilometer. The capability to detect cloud bases was compared to the Cloudnet feature mask, and the good agreement gives evidence that this feature could be used to apply robust cloud screening, which is often needed for lidar data retrievals, for example, for other automatic approaches such as the EARLINET Single Calculus Chain (D'Amico et al., 2015). Ice crystals were also often classified correctly but sometimes remained unclassified or were even falsely classified as aerosol as a consequence of multiple reasons (a priori information aiming at aerosol, low depolarizing characteristics in certain temperature ranges, etc.). This behaviour might be overcome when combining the lidar stand-alone target categorization with the Cloudnet target categorization as planned in ACTRIS- $2^{2}$. Then, the 10 lidar-based target types are available in addition to the already existing Cloudnet quantities for an advanced categorization of both aerosol and clouds. In this way, errors, i.e. misclassifications, could be minimized in both schemes

\footnotetext{
${ }^{2}$ ACTRIS is the European Research Infrastructure for the observation of Aerosol, Clouds, and Trace gases: http://www.actris.eu/.
}

and a detailed data set could be provided for European and other supersites hosting both Cloudnet standard equipment and reliable, automatic, high-quality lidars based on EARLINET standards.

However, it is important to have a lidar stand-alone tool, as at the moment Cloudnet and automatic continuously running MWLs are operated only at three European stations, while stand-alone lidar systems are available at more than 25 EARLINET stations. We also consider the presented MWL approach for the classification of aerosol types as a prerequisite for the development of schemes for the identification of aerosol layers. Current retrievals, such as the STRAT algorithm (Morille et al., 2007), aim for providing aerosol layering information from lidar observations at one wavelength and can thus only identify a single layer even though it would actually consist of several layers of different types, such as smoke or dust. With this development, the integration of EARLINET and Cloudnet is ongoing and offers a high potential for future synergistic profiling of aerosols, clouds, and their interaction by combining modern state-of-the-art atmospheric instruments.

Data availability. The calibrated lidar signals and the lidar and cloudnet target categorization are available via the SAMD data archive: https://icdc.cen.uni-hamburg.de/index.php?id=samd (see Stamnas et al., 2016 for more information). Lidar quicklooks can be found at polly.tropos.de. AERONET data are available via https://aeronet.gsfc.nasa.gov/cgi-bin/type_one_station_opera_v2_ new? site $=$ HOPE-Krauthausen $\&$ nachal $=0 \&$ year $=21 \&$ aero_water $=$ $0 \&$ if_day $=0 \&$ year_or_month $=1 \&$ level $=3 \&$ place_code $=4$. GDAS 1 data are available via https://www.ready.noaa.gov/gdas1.php. 


\section{Appendix A: Measurement overview}
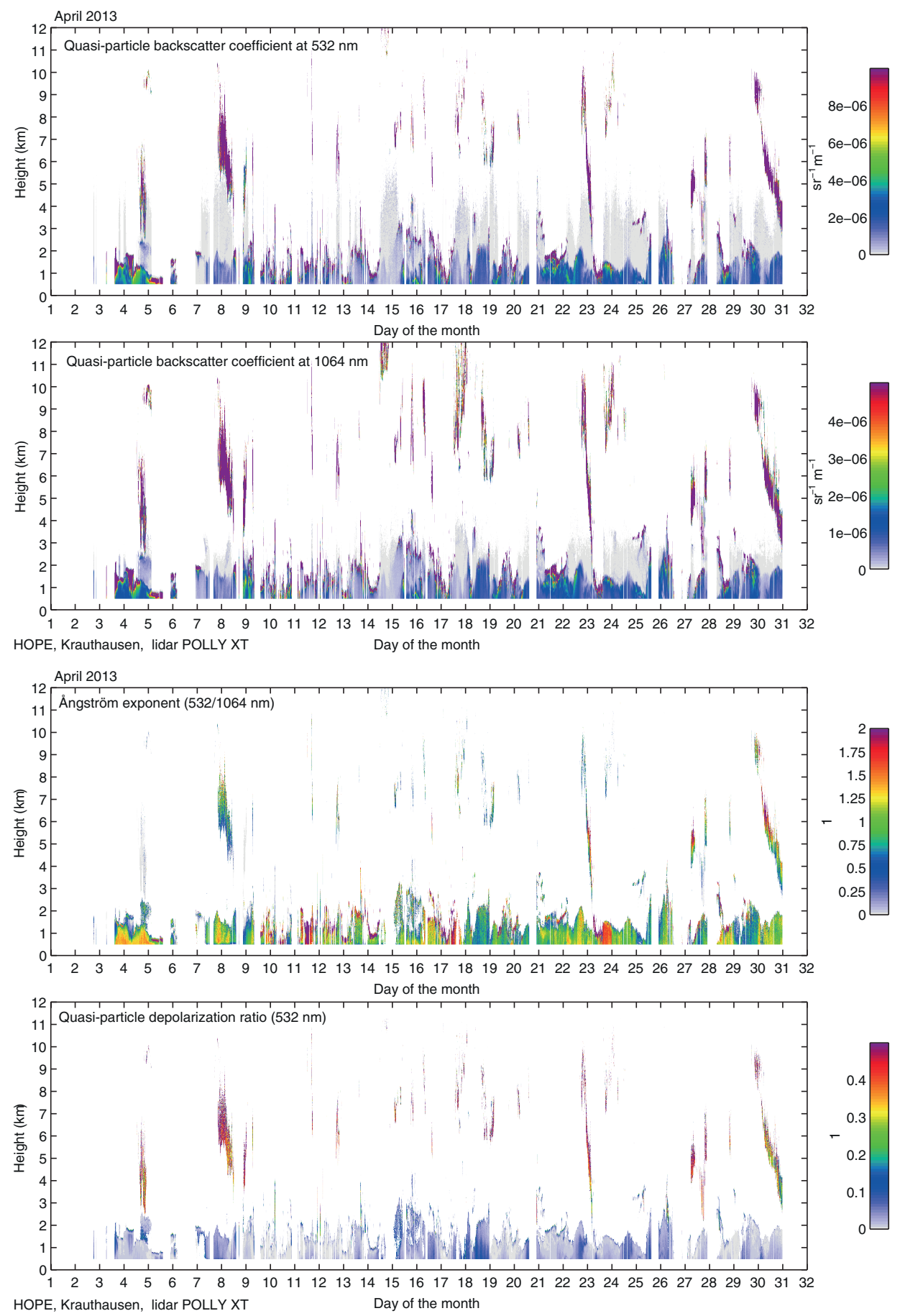

Figure A1. Overview of MWL Polly XT observations in April 2013. Top to bottom: quasi-particle-backscatter coefficient at 532 and 1064 nm, corresponding Ångström exponent, and quasi-particle depolarization ratio at $532 \mathrm{~nm}$. 

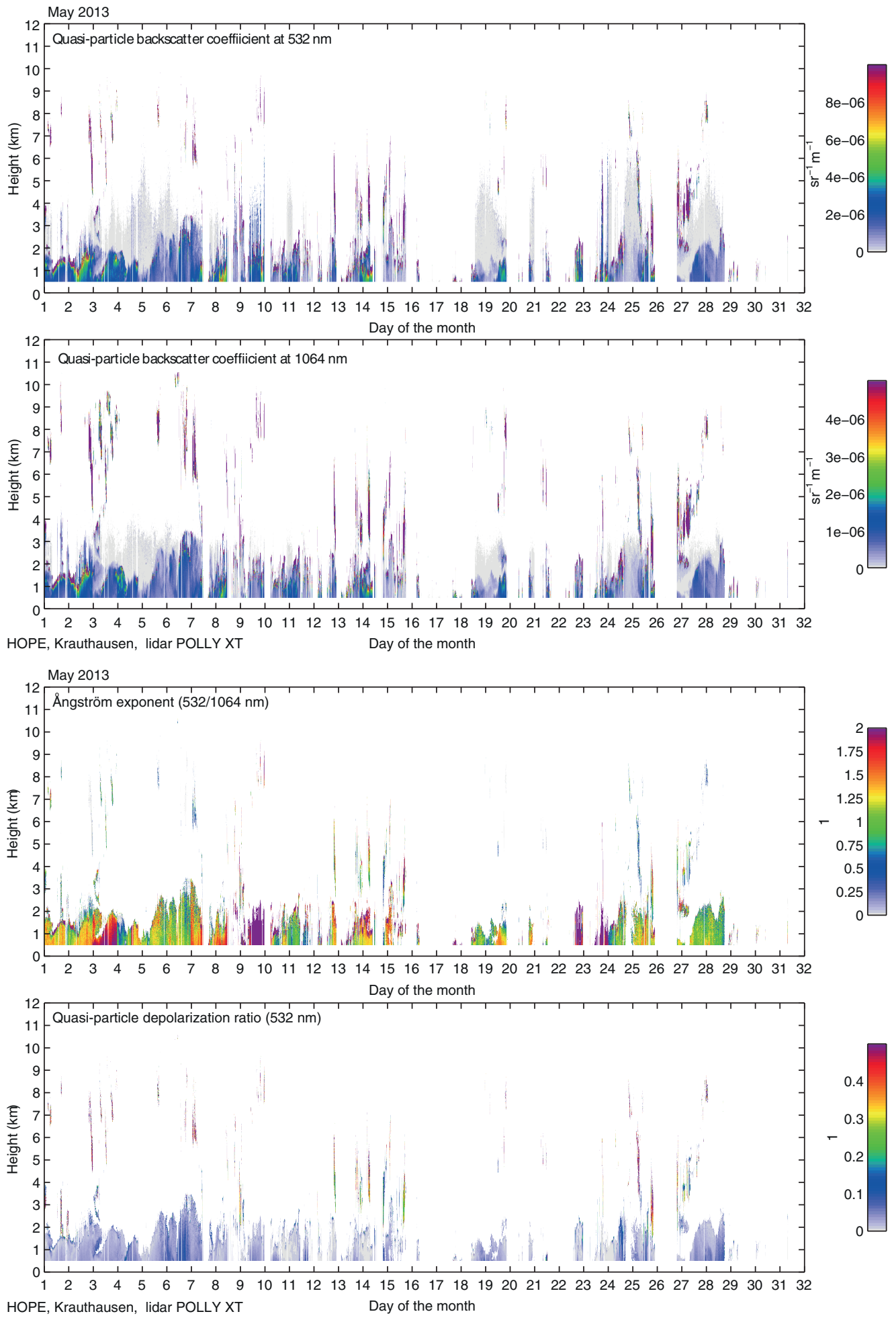

Figure A2. Overview of MWL Polly XT observations in May 2013. Top to bottom: quasi-particle-backscatter coefficient at 532 and 1064 nm, corresponding Ångström exponent, and quasi-particle depolarization ratio at $532 \mathrm{~nm}$. 
Competing interests. The authors declare that they have no conflict of interest.

Special issue statement. This article is part of the special issue "HD(CP)2 Observational Prototype Experiment (ACP/AMT interjournal SI)". It is not associated with a conference.

Acknowledgements. The authors acknowledge support through the High-Definition Clouds and Precipitation for advancing Climate Prediction research program $\left(\mathrm{HD}(\mathrm{CP})^{2}\right.$; FKZ: 01LK1209C and 01LK1212C) funded by Federal Ministry of Education and Research in Germany (BMBF), ACTRIS under grant agreement no. 262254 and ITaRS under grant agreement no. 289923 of the European Union Seventh Framework Programme (FP7/2007-2013), and ACTRIS-2 under grant agreement no. 654109 from the European Union's Horizon 2020 research and innovation programme. Many improvements, both in terms of hardware and software, were triggered by the fruitful discussions and network activities within EARLINET. The software framework of Cloudnet was used for this development for which the authors are grateful. We also acknowledge the use of JOYCE data which are provided via the $\mathrm{HD}(\mathrm{CP})^{2}$ data portal.

Edited by: Stefan Buehler

Reviewed by: two anonymous referees 


\section{References}

Althausen, D., Engelmann, R., Baars, H., Heese, B., Ansmann, A., Müller, D., and Komppula, M.: Portable Raman lidar PollyXT for automated profiling of aerosol backscatter, extinction, and depolarization, J. Atmos. Ocean. Tech., 26, 2366-2378, https://doi.org/10.1175/2009JTECHA1304.1, 2009.

Amiridis, V., Marinou, E., Tsekeri, A., Wandinger, U., Schwarz, A., Giannakaki, E., Mamouri, R., Kokkalis, P., Binietoglou, I., Solomos, S., Herekakis, T., Kazadzis, S., Gerasopoulos, E., Proestakis, E., Kottas, M., Balis, D., Papayannis, A., Kontoes, C., Kourtidis, K., Papagiannopoulos, N., Mona, L., Pappalardo, G., Le Rille, O., and Ansmann, A.: LIVAS: a 3-D multi-wavelength aerosol/cloud database based on CALIPSO and EARLINET, Atmos. Chem. Phys., 15, 7127-7153, https://doi.org/10.5194/acp15-7127-2015, 2015.

Ångström, A.: The parameters of atmospheric turbidity, Tellus, 16, 64-75, 1964.

Ansmann, A., Riebesell, M., Wandinger, U., Weitkamp, C., Voss, E., Lahmann, W., and Michaelis, W.: LIDAR for vertical profiling of moisture, aerosol extinction, backscatter, and LIDAR ratio, Applied Physics B, 55, 18-28, http://ams.allenpress.com/perlserv/?request=get-abstract\&issn= $1520-0469 \&$ volume $=026 \&$ issue $=02 \&$ page $=0315,1992 \mathrm{a}$.

Ansmann, A., Wandinger, U., Riebesell, M., Weitkamp, C., and Michaelis, W.: Independent measurement of extinction and backscatter profiles in cirrus clouds by using a combined Raman elastic-backscatter lidar, Appl. Optics, 31, 7113-7131, https://doi.org/10.1364/AO.31.007113, 1992b.

Ansmann, A., Petzold, A., Kandler, K., Tegen, I., Wendisch, M., Müller, D., Weinzierl, B., Müller, T., and Heintzenberg, J.: Saharan mineral dust experiments SAMUM-1 and SAMUM-2: what have we learned?, Tellus B, 63, 403-429, https://doi.org/10.1111/j.1600-0889.2011.00555.x, 2011.

Baars, H., Kanitz, T., Engelmann, R., Althausen, D., Heese, B., Komppula, M., Preißler, J., Tesche, M., Ansmann, A., Wandinger, U., Lim, J.-H., Ahn, J. Y., Stachlewska, I. S., Amiridis, V., Marinou, E., Seifert, P., Hofer, J., Skupin, A., Schneider, F., Bohlmann, S., Foth, A., Bley, S., Pfüller, A., Giannakaki, E., Lihavainen, H., Viisanen, Y., Hooda, R. K., Pereira, S. N., Bortoli, D., Wagner, F., Mattis, I., Janicka, L., Markowicz, K. M., Achtert, P., Artaxo, P., Pauliquevis, T., Souza, R. A. F., Sharma, V. P., van Zyl, P. G., Beukes, J. P., Sun, J., Rohwer, E. G., Deng, R., Mamouri, R.-E., and Zamorano, F.: An overview of the first decade of Polly NET: an emerging network of automated Raman-polarization lidars for continuous aerosol profiling, Atmos. Chem. Phys., 16, 51115137, https://doi.org/10.5194/acp-16-5111-2016, 2016.

Behrendt, A. and Nakamura, T.: Calculation of the calibration constant of polarization lidar and its dependency on atmospheric temperature, Opt. Express, 10, 805-817, https://doi.org/10.1364/OE.10.000805, 2002.

Bucholtz, A.: Rayleigh-scattering calculations for the terrestrial atmosphere, Appl. Optics, 34, 2765-2773, 1995.

Bühl, J., Seifert, P., Wandinger, U., Baars, H., Kanitz, T., Schmidt, J., Myagkov, A., Engelmann, R., Skupin, A., Heese, B., Klepel, A., Althausen, D., and Ansmann, A.: LACROS: the Leipzig aerosol and cloud remote observations system, in: SPIE Remote Sensing of Clouds and the Atmosphere XVIII; and Optics in Atmospheric Propagation and Adaptive Systems XVI,
Proc. SPIE 8890, Remote Sensing of Clouds and the Atmosphere XVIII; and Optics in Atmospheric Propagation and Adaptive Systems XVI, 889002, https://doi.org/10.1117/12.2030911, 2013.

Burton, S. P., Ferrare, R. A., Hostetler, C. A., Hair, J. W., Rogers, R. R., Obland, M. D., Butler, C. F., Cook, A. L., Harper, D. B., and Froyd, K. D.: Aerosol classification using airborne High Spectral Resolution Lidar measurements methodology and examples, Atmos. Meas. Tech., 5, 73-98, https://doi.org/10.5194/amt-5-73-2012, 2012.

Cairo, F., di Donfrancesco, G., Adriani, A., Pulvirenti, L., and Fierli, F.: Comparison of various linear depolarization parameters measured by lidar, Appl. Optics, 38, 4425-4432, http://www. opticsinfobase.org/abstract.cfm?id=60738, 1999.

D’Amico, G., Amodeo, A., Baars, H., Binietoglou, I., Freudenthaler, V., Mattis, I., Wandinger, U., and Pappalardo, G.: EARLINET Single Calculus Chain - overview on methodology and strategy, Atmos. Meas. Tech., 8, 4891-4916, https://doi.org/10.5194/amt-8-4891-2015, 2015.

Engelmann, R., Kanitz, T., Baars, H., Heese, B., Althausen, D., Skupin, A., Wandinger, U., Komppula, M., Stachlewska, I. S., Amiridis, V., Marinou, E., Mattis, I., Linné, H., and Ansmann, A.: The automated multiwavelength Raman polarization and water-vapor lidar Polly XT: the neXT generation, Atmos. Meas. Tech., 9, 1767-1784, https://doi.org/10.5194/amt-9-1767-2016, 2016.

Fernald, F. G.: Analysis of atmospheric lidar observations - some comments, Appl. Optics, 23, 652-653, 1984.

Freudenthaler, V.: Lidar Rayleigh-fit criteria, in: EARLINET-ASOS 7th Workshop, available at: http://nbn-resolving.de/urn/resolver. pl?urn=nbn:de:bvb:19-epub-12970-6 (last access: 11 February 2015), 2009.

Freudenthaler, V.: About the effects of polarising optics on lidar signals and the $\Delta 90$ calibration, Atmos. Meas. Tech., 9, 41814255, https://doi.org/10.5194/amt-9-4181-2016, 2016.

Giannakaki, E., Pfüller, A., Korhonen, K., Mielonen, T., Laakso, L., Vakkari, V., Baars, H., Engelmann, R., Beukes, J. P., Van Zyl, P. G., Josipovic, M., Tiitta, P., Chiloane, K., Piketh, S., Lihavainen, H., Lehtinen, K. E. J., and Komppula, M.: One year of Raman lidar observations of free-tropospheric aerosol layers over South Africa, Atmos. Chem. Phys., 15, 5429-5442, https://doi.org/10.5194/acp-15-5429-2015, 2015.

Gouveia, D. A., Barja, B., Barbosa, H. M. J., Seifert, P., Baars, H., Pauliquevis, T., and Artaxo, P.: Optical and geometrical properties of cirrus clouds in Amazonia derived from 1 year of groundbased lidar measurements, Atmos. Chem. Phys., 17, 3619-3636, https://doi.org/10.5194/acp-17-3619-2017, 2017.

Groß, S., Esselborn, M., Weinzierl, B., Wirth, M., Fix, A., and Petzold, A.: Aerosol classification by airborne high spectral resolution lidar observations, Atmos. Chem. Phys., 13, 2487-2505, https://doi.org/10.5194/acp-13-2487-2013, 2013.

Groß, S., Freudenthaler, V., Wirth, M., and Weinzierl, B.: Towards an aerosol classification scheme for future EarthCARE lidar observations and implications for research needs, Atmos. Sci. Lett., 16, 77-82, https://doi.org/10.1002/as12.524, 2015.

Hess, M., Koepke, P., and Schult, I.: Optical properties of aerosols and clouds: the software package OPAC, B. Am. Meteorol. Soc., 79, 831-844, https://doi.org/10.1175/15200477(1998)079<0831:OPOAAC>2.0.CO;2, 1998. 
Hogan, R. J. and O'Connor, E. J.: Facilitating cloud radar and lidar algorithms: the Cloudnet Instrument Synergy/Target Categorization product, Dept. of Meteorol. Univ. of Reading, UK, available at: http://www.met.reading.ac.uk/ swrhgnrj/publications/ categorization.pdf (last access: July 2016), 2004.

Holben, B. N., Tanré, D., Smirnov, A., Eck, T. F., Slutsker, I., Abuhassan, N., Newcomb, W. W., Schafer, J. S., Chatenet, B., Lavenu, F., Kaufman, Y. J., Castle, J. V., Setzer, A., Markham, B., Clark, D., Frouin, R., Halthore, R., Karneli, A., O’Neill, N. T., Pietras, C., Pinker, R. T., Voss, K., and Zibordi, G.: An emerging ground-based aerosol climatology: aerosol optical depth from AERONET, J. Geophys. Res., 106, 12067-12098, https://doi.org/10.1029/2001JD900014, 2001.

Hu, Y., Winker, D., Vaughan, M., Lin, B., Omar, A., Trepte, C., Flittner, D., Yang, P., Nasiri, S. L., Baum, B., Sun, W., Liu, Z., Wang, Z., Young, S., Stamnes, K., Huang, J., Kuehn, R., and Holz, R.: CALIPSO/CALIOP cloud phase discrimination algorithm, J. Atmos. Ocean. Tech., 26, 2293, https://doi.org/10.1175/2009JTECHA1280.1, 2009.

Illingworth, A. J., Hogan, R. J., O'Connor, E. J., Bouniol, D., Brooks, M. E., Delanoë, J., Donovan, D. P., Eastment, J. D., Gaussiat, N., Goddard, J. W. F., Haeffelin, M., Baltink, H. K., Krasnov, O. A., Pelon, J., Piriou, J.-M., Protat, A., Russchenberg, H. W. J., Seifert, A., Tompkins, A. M., van Zadelhoff, G.-J., Vinit, F., Willén, U., Wilson, D. R., and Wrench, C. L.: Cloudnet - continuous evaluation of cloud profiles in seven operational models using ground-based observations, B. Am. Meteorol. Soc., 88, 883-898, http://ams.allenpress.com/perlserv/?request= get-abstract\&doi=10.1175\%2FBAMS-88-6-883, 2007.

Illingworth, A. J., Barker, H. W., Beljaars, A., Ceccaldi, M., Chepfer, H., Cole, J., Delanoë, J., Domenech, C., Donovan, D. P., Fukuda, S., Hirakata, M., Hogan, R. J., Huenerbein, A., Kollias, P., Kubota, T., Nakajima, T., Nakajima, T. Y., Nishizawa, T., Ohno, Y., Okamoto, H., Oki, R., Sato, K., Satoh, M., Shephard, M., Wandinger, U., Wehr, T., and Van Zadelhoff, G.-J.: The EarthCARE Satellite: The Next Step Forward in Global Measurements of Clouds, Aerosols, Precipitation, and Radiation. Bull. Amer. Meteor. Soc., 96, 1311-1332, https://doi.org/10.1175/BAMS-D-12-00227.1, 2015.

IPCC: Climate Change 2013: The Physical Science Basis. Contribution of Working Group I to the Fifth Assessment Report of the Intergovernmental Panel on Climate Change, Cambridge University Press, Cambridge, UK and New York, NY, USA, https://doi.org/10.1017/CBO9781107415324, 2013.

Kienast-Sjögren, E., Rolf, C., Seifert, P., Krieger, U. K., Luo, B. P., Krämer, M., and Peter, T.: Climatological and radiative properties of midlatitude cirrus clouds derived by automatic evaluation of lidar measurements, Atmos. Chem. Phys., 16, 7605-7621, https://doi.org/10.5194/acp-16-7605-2016, 2016.

Klett, J.: Stable analytical inversion solution for processing lidar returns, Appl. Optics, 20, 211-220, 1981.

Liu, Z., Vaughan, M., Winker, D., Kittaka, C., Getzewich, B., Kuehn, R., Omar, A., Powell, K., Trepte, C., and Hostetler, C.: The CALIPSO lidar cloud and aerosol discrimination: Version 2 algorithm and initial assessment of performance, J. Atmos. Ocean. Tech., 26, 1198, http://ams.allenpress.com/perlserv/ ?request=get-abstract $\&$ doi $=10.1175 \% 2$ F2009JTECHA1229.1, 2009.
Macke, A., Seifert, P., Baars, H., Barthlott, C., Beekmans, C., Behrendt, A., Bohn, B., Brueck, M., Bühl, J., Crewell, S., Damian, T., Deneke, H., Düsing, S., Foth, A., Di Girolamo, P., Hammann, E., Heinze, R., Hirsikko, A., Kalisch, J., Kalthoff, N., Kinne, S., Kohler, M., Löhnert, U., Madhavan, B. L., Maurer, V., Muppa, S. K., Schween, J., Serikov, I., Siebert, H., Simmer, C., Sph, F., Steinke, S., Trümner, K., Trömel, S., Wehner, B., Wieser, A., Wulfmeyer, V., and Xie, X.: The $\mathrm{HD}(\mathrm{CP})^{2}$ Observational Prototype Experiment (HOPE) an overview, Atmos. Chem. Phys., 17, 4887-4914, https://doi.org/10.5194/acp17-4887-2017, 2017.

Marshall, J. S. and Palmer, W. M. K.: The distribution of raindrops with size, J. Meteorol., $\quad 5, \quad 165-166, \quad$ https://doi.org/10.1175/15200469(1948)005<0165:TDORWS>2.0.CO;2, 1948.

Mather, J. H. and Voyles, J. W.: The ARM climate research facility: a review of structure and capabilities, B. Am. Meteorol. Soc., 94, 377-392, https://doi.org/10.1175/BAMS-D-11-00218.1, 2013.

Mattis, I., Ansmann, A., Müller, D., Wandinger, U., and Althausen, D.: Multiyear aerosol observations with dual-wavelength Raman lidar in the framework of EARLINET, J. Geophys. Res.-Atmos., 109, d13203, https://doi.org/10.1029/2004JD004600, 2004.

Maurer, V., Kalthoff, N., Wieser, A., Kohler, M., Mauder, M., and Gantner, L.: Observed spatiotemporal variability of boundarylayer turbulence over flat, heterogeneous terrain, Atmos. Chem. Phys., 16, 1377-1400, https://doi.org/10.5194/acp-161377-2016, 2016.

Morille, Y., Haeffelin, M., Drobinski, P., and Pelon, J.: STRAT: an automated algorithm to retrieve the vertical structure of the atmosphere from single-channel lidar data, J. Atmos. Ocean. Tech., 24, 761-775, https://doi.org/10.1175/JTECH2008.1, 2007.

Müller, D., Ansmann, A., Mattis, I., Tesche, M., Wandinger, U., Althausen, D., and Pisani, G.: Aerosol-type-dependent lidar ratios observed with Raman lidar, J. Geophys. Res., 112, D16202, https://doi.org/10.1029/2006JD008292, 2007.

Müller, D., Böckmann, C., Kolgotin, A., Schneidenbach, L., Chemyakin, E., Rosemann, J., Znak, P., and Romanov, A.: Microphysical particle properties derived from inversion algorithms developed in the framework of EARLINET, Atmos. Meas. Tech., 9, 5007-5035, https://doi.org/10.5194/amt-9-5007-2016, 2016.

Omar, A. H., Winker, D. M., Kittaka, C., Vaughan, M. A., Liu, Z., Hu, Y., Trepte, C. R., Rogers, R. R., Ferrare, R. A., Lee, K.-P., Kuehn, R. E., and Hostetler, C. A.: The CALIPSO automated aerosol classification and lidar ratio selection algorithm, J. Atmos. Ocean. Tech., 26, 1994, https://doi.org/10.1175/2009JTECHA1231.1, 2009.

Pappalardo, G., Mona, L., D’Amico, G., Wandinger, U., Adam, M., Amodeo, A., Ansmann, A., Apituley, A., Alados Arboledas, L., Balis, D., Boselli, A., Bravo-Aranda, J. A., Chaikovsky, A., Comeron, A., Cuesta, J., De Tomasi, F., Freudenthaler, V., Gausa, M., Giannakaki, E., Giehl, H., Giunta, A., Grigorov, I., Groß, S., Haeffelin, M., Hiebsch, A., Iarlori, M., Lange, D., Linné, H., Madonna, F., Mattis, I., Mamouri, R.-E., McAuliffe, M. A. P., Mitev, V., Molero, F., Navas-Guzman, F., Nicolae, D., Papayannis, A., Perrone, M. R., Pietras, C., Pietruczuk, A., Pisani, G., Preißler, J., Pujadas, M., Rizi, V., Ruth, A. A., Schmidt, J., Schnell, F., Seifert, P., Serikov, I., Sicard, M., Simeonov, V., Spinelli, N., Stebel, K., Tesche, M., Trickl, T., Wang, X., Wag- 
ner, F., Wiegner, M., and Wilson, K. M.: Four-dimensional distribution of the 2010 Eyjafjallajökull volcanic cloud over Europe observed by EARLINET, Atmos. Chem. Phys., 13, 4429-4450, https://doi.org/10.5194/acp-13-4429-2013, 2013.

Schwarz, A.: Aerosol typing over Europe and its benefits for the CALIPSO and EarthCARE missions - Statistical analysis based on multiwavelength aerosol lidar measurements from ground-based EARLINET stations and comparison to spaceborne CALIPSO data, PhD thesis, University of Leipzig, Germany, 2016.

Seifert, P., Ansmann, A., Müller, D., Wandinger, U., Althausen, D., Heymsfield, A. J., Massie, S. T., and Schmitt, C.: Cirrus optical properties observed with lidar, radiosonde, and satellite over the tropical Indian Ocean during the aerosol-polluted northeast and clean maritime southwest monsoon, J. Geophys. Res., 112, D17205, https://doi.org/10.1029/2006JD008352, 2007.

Shimizu, A., Sugimoto, N., and Matsui, I.: Detailed description of data processing system for lidar network in East Asia, in: 25th International Laser Radar Conference, 5-9 July 2010, St. Petersburg, Russi, 911-913, 2010.

Skupin, A., Ansmann, A., Engelmann, R., Baars, H., and Müller, T.: The Spectral Aerosol Extinction Monitoring System (SÆMS): setup, observational products, and comparisons, Atmos. Meas. Tech., 7, 701-712, https://doi.org/10.5194/amt-7701-2014, 2014.

Stamnas, E., Lammert, A., Winkelmann, V., and Lang, U.: The $\mathrm{HD}(\mathrm{CP}) 2$ Data Archive for Atmospheric Measurement Data, ISPRS International Journal of Geo-Information, 5, 124, https://doi.org/10.3390/ijgi5070124, 2016.

Stephens, G. L., Vane, D. G., Boain, R. J., Mace, G. G., Sassen, K., Wang, Z., Illingworth, A. J., O’Connor, E. J., Rossow, W. B., Durden, S. L., Miller, S. D., Austin, R. T., Benedetti, A., Mitrescu, C., and Team, T. C. S.: The Cloudsat mission and the A-train, B. Am. Meteorol. Soc., 83, 1771-1790, http://ams.allenpress.com/perlserv/?request=get-abstract\&issn= 1520-0477\&volume $=083 \&$ issue $=12 \&$ page $=1771,2002$.

Stoffelen, A., Pailleux, J., Källén, E., Vaughan, J. M., Isaksen, L., Flamant, P., Wergen, W., Andersson, E., Schyberg, H., Culoma, A., Meynart, R., Endemann, M., and Ingmann, P.: The atmospheric dynamics mission for global wind field measurement, B. Am. Meteorol. Soc., 86, 73-87, https://doi.org/10.1175/BAMS-86-1-73, 2005.

Sugimoto, N., Nishizawa, T., Shimizu, A., Matsui, I., and Jin, Y.: Characterization of aerosols in East Asia with the Asian Dust and Aerosol Lidar Observation Network (ADNet), in: Proc. SPIE, vol. 9262, pp. 92620K-92620K-9, https://doi.org/10.1117/12.2069892, 2014.

Tesche, M., Ansmann, A., Müller, D., Althausen, D., Engelmann, R., Freudenthaler, V., and Groß, S.: Vertically resolved separation of dust and smoke over Cape Verde using multiwavelength Raman and polarization lidars during Saharan Mineral Dust Experiment 2008, J. Geophys. Res., 114, D13202, https://doi.org/10.1029/2009JD011862, 2009a.
Tesche, M., Ansmann, A., Müller, D., Althausen, D., Mattis, I., Heese, B., Freudenthaler, V., Wiegner, M., Esselborn, M., Pisani, G., and Knippertz, P.: Vertical profiling of Saharan dust with Raman lidars and airborne HSRL in southern Morocco during SAMUM, Tellus B, 61, 144-164, http://www3.interscience. wiley.com/journal/121504427/abstract, 2009b.

Tesche, M., Gross, S., Ansmann, A., Müller, D., Althausen, D., Freudenthaler, V., and Esselborn, M.: Profiling of Saharan dust and biomass-burning smoke with multiwavelength polarization Raman lidar at Cape Verde, Tellus B, 63, 649-676, https://doi.org/10.1111/j.1600-0889.2011.00548.x, 2011.

Thorsen, T. J., Fu, Q., Newsom, R. K., Turner, D. D., and Comstock, J. M.: Automated retrieval of cloud and aerosol properties from the ARM Raman lidar, Part I: Feature detection, J. Atmos. Ocean. Tech., 32, 1977-1998, https://doi.org/10.1175/JTECHD-14-00150.1, 2015.

Veselovskii, I., Whiteman, D. N., Korenskiy, M., Suvorina, A., Kolgotin, A., Lyapustin, A., Wang, Y., Chin, M., Bian, H., Kucsera, T. L., Pérez-Ramírez, D., and Holben, B.: Characterization of forest fire smoke event near Washington, DC in summer 2013 with multi-wavelength lidar, Atmos. Chem. Phys., 15, 1647-1660, https://doi.org/10.5194/acp-15-1647-2015, 2015.

Wandinger, U. and Ansmann, A.: Experimental determination of the lidar overlap profile with Raman lidar, Appl. Optics, 41, 511514, 2002.

Wandinger, U., Baars, Holger, Engelmann, R., Hünerbein, A., Horn, S., Kanitz, T., Donovan, D., van Zadelhoff, G.-J., Daou, D., Fischer, J., von Bismarck, J., Filipitsch, F., Docter, N., Eisinger, M., Lajas, D., and Wehr, T.: HETEAC: the aerosol classification model for EarthCARE, EPJ Web Conf., 119, 01004, https://doi.org/10.1051/epjconf/201611901004, 2016.

Westbrook, C. D., Illingworth, A. J., O'Connor, E. J., and Hogan, R. J.: Doppler lidar measurements of oriented planar ice crystals falling from supercooled and glaciated layer clouds, Q. J. Roy. Meteor. Soc., 136, 260-276, 2009.

Winker, D. M., Vaughan, M. A., Omar, A., Hu, Y., Powell, K. A., Liu, Z., Hunt, W. H., and Young, S. A.: Overview of the CALIPSO mission and CALIOP data processing algorithms, J. Atmos. Ocean. Tech., 26, 2310-2323, 2009.

Yorks, J. E., McGill, M. J., Palm, S. P., Hlavka, D. L., Selmer, P. A., Nowottnick, E. P., Vaughan, M. A., Rodier, S. D., and Hart, W. D.: An overview of the CATS level 1 processing algorithms and data products, Geophys. Res. Lett., 43, 4632-4639, https://doi.org/10.1002/2016GL068006, 2016. 